\title{
Descriptions of eighteen new species of Glemparon, a previously monotypic genus of Porricondylinae (Diptera, Cecidomyiidae)
}

\author{
Mathias JASCHHOF ${ }^{1, *}$ \& Catrin JASCHHOF ${ }^{2}$ \\ ${ }^{1,2}$ Station Linné, Ölands Skogsby 161, SE-38693 Färjestaden, Sweden. \\ *Corresponding author: mjaschhof@yahoo.de \\ 2Email: cjaschhof@yahoo.de \\ ${ }^{1}$ urn:1sid:zoobank.org:author:8B4B11B4-7C33-41AC-A042-AA9903CDC4B1 \\ ${ }^{2}$ urn:lsid:zoobank.org:author:BE4CA083-88F6-4037-826D-605FFF5078F7
}

\begin{abstract}
Glemparon Jaschhof, 2013, a previously monotypic genus confined to Sweden, is shown here to be considerably richer in species, with most species found to occur in the Australasian region. Eighteen new species are described: G. tomelilla sp. nov. (from Sweden); G. aotearoa sp. nov., G. birhojohmi sp. nov., G. cervus sp. nov., G. didhami sp. nov, G. kaikoura sp. nov., G. nativitas sp. nov., G. orautahi sp. nov., G. otago sp. nov., G. pureora sp. nov., G. rakiura sp. nov., G. rotoiti sp. nov., G. rotoroa sp. nov., G. tewaipounamu sp. nov., G. waipapa sp. nov., G. waipoua sp. nov. (all from New Zealand); G. manuka sp. nov. and G. warra sp. nov. (both from Tasmania, Australia). Glemparon sagittifer Jaschhof, 2013 is redescribed. Genitalic illustrations are provided allowing for the effective identification of all the species known thus far. Morphological data obtained here are used for revising the generic definition. Dicerura Kieffer, 1898 is hypothesized as the sister group to Glemparon. The case of Glemparon is discussed as a perfect example of the fact that our collective ignorance of porricondyline diversity in most parts of the world is a major impediment to a better understanding of the European species.
\end{abstract}

Keywords. Gall midges, fungivores, Sweden, New Zealand, Australia.

Jaschhof M. \& Jaschhof C. 2018. Descriptions of eighteen new species of Glemparon, a previously monotypic genus of Porricondylinae (Diptera, Cecidomyiidae). European Journal of Taxonomy 450: 1-38.

https://doi.org/10.5852/ejt.2018.450

\section{Introduction}

The genus Glemparon Jaschhof, 2013 was introduced to absorb a single, unusual species of dicerurine Porricondylinae, of which two males had been captured by The Swedish Malaise Trap Project in two places in southern Sweden (Jaschhof \& Jaschhof 2013). Morphological analysis revealed this species, Glemparon sagittifer Jaschhof, 2013, to differ from all other Dicerurini by the presence of setae on both the postfrons and the metepisternum. Other distinctions found concern genitalic structures: the ventral gonocoxal emargination, which is provided with a complex, largely membranous outgrowth (revised and called the posteromedial protuberance in the present paper) and the tegmen, which has two pairs of processes (Jaschhof \& Jaschhof 2013: fig. 64A-B). As both specimens of G. sagittifer available 
for description were lacking the antennal apices, the number of flagellomeres (one of the standard taxonomic characters in Porricondylinae) could not be determined. The affiliation of G. sagittifer to other Dicerurini could not be resolved, partly due to the many morphological peculiarities, partly due to the fact that so much of the diversity of world Dicerurini remains undescribed, rendering it unavailable for comparison. This unsatisfactory situation began to change with our recent discovery of an unnamed congener of G. sagittifer in previously unstudied Malaise material from Sweden; again two males from two sites in the south of the country. Closer study of the morphology of this species, named here G. tomelilla sp. nov., revealed structures that reminded one of us (MJ) of similar-looking species he had studied a few years ago, from New Zealand. Reinvestigation of these species, which until then remained as unnamed Dicerurini of unresolved generic affiliation, confirmed that they belong to the genus Glemparon. In addition, two more unnamed species of Glemparon were identified among a few Porricondylinae specimens we had at our disposal from Tasmania. All these new species, altogether 18 , are described and named here, thereby documenting remarkable species richness in a previously monotypic genus. New morphological data are used for revising the generic definition. Glemparon is hypothesized to be the sister group to Dicerura Kieffer, 1898, a genus of 32 named species in the Holarctic region (Jaschhof \& Spungis 2018). The odd, disjunct distribution of Glemparon, now with two Palearctic and 17 Australasian species, is discussed.

\section{Material and methods}

Of the two Swedish species of Glemparon, a total of four male specimens were obtained from The Swedish Malaise Trap Project (SMTP; http://www.stationlinne.se/sv/forskning/the-swedish-malaise-trap-projectsmtp, accessed 8 Mar. 2018) and The Gall Midge Project(http://www.stationlinne.se/sv/forskning/the-gallmidge-project, accessed 8 Mar. 2018). Specimens from New Zealand, altogether 19 males, come from Malaise samples that we studied during our "Lestremiinae of New Zealand" project (2001-2003; see Jaschhof \& Jaschhof 2003). Two Glemparon males from Tasmania were picked from Malaise samples provided by The Tasmanian Forest Insect Collection in the care of Forestry Tasmania, Hobart (see Jaschhof \& Jaschhof 2008). All in all, 24 specimens were studied and identified here as belonging to 19 different species. Our specimens from Sweden result from studying hundreds of Malaise samples from all over Sweden for new or otherwise interesting Porricondylinae, while the specimens from New Zealand and Tasmania were picked out merely for curiosity and should therefore be regarded as chance by-products from gathering material of Lestremiinae and Micromyinae, our focal taxa at that time.

\section{Institutional abbreviations}

Types and other voucher specimens of the species studied here are available as microscopic preparations (Canada balsam inclusions) deposited in the following collections:

AM $=$ Australian Museum, Sydney, Australia
NHRS $=$ Naturhistoriska Riksmuseet Stockholm, Sweden
NZAC $=$ New Zealand Arthropod Collection, Tamaki, Auckland, New Zealand
SDEI $=$ Senckenberg Deutsches Entomologisches Institut, Müncheberg, Germany

The procedures of specimen preparation and identification as well as the morphological terminology used in adult Porricondylinae were recently described by Jaschhof \& Jaschhof (2013). Several morphological terms, some of which specific to Glemparon, are explained in Figs 2-3, 6 and 15 of the present paper. Body length, measured on slide-mounted specimens, is given including the genitalia. The gonocoxites of male Porricondylinae, including Glemparon, are merged into a single structure and thus described as a unit. Both the cerci and hypoproct are not described (nor illustrated) here; they might have taxonomic merit, but, since they tend to distort and be overlayed by other structures, are difficult to study. Arrows are used to highlight important diagnostic characters in both the wording and illustrations of a taxonomic description, with numbers 
referring to particular characters $\left(\downarrow^{1}, \downarrow^{2}, \downarrow^{3}\right.$, etc.). Descriptive sections other than diagnoses, titled here "Other characters", make mention only of those characters not referred to before. Species are treated according to geographical distribution (Sweden, New Zealand, Tasmania) and, within this scheme, in alphabetical order. Most of the new species are named after geographic localities, with names used as nouns in apposition as to retain their euphony. Exceptions to this practice are explained in the respective etymology sections.

\title{
Results
}

\author{
Class Insecta Linnaeus, 1758 \\ Order Diptera Linnaeus, 1804 \\ Suborder Bibionomorpha Hennig, 1954 \\ Family Cecidomyiidae Newman, 1834 \\ Subfamily Porricondylinae Kieffer, 1913
}

Genus Glemparon Jaschhof, 2013

\section{Diagnosis}

Glemparon is known only from males; females and larvae remain unrecognized. Unprecedented within Dicerurini, the number of flagellomeres varies among different species of Glemparon from 12 to 18, as far as is known. Basitarsal spines are either present (Fig. 1A) or absent (Fig. 1B), which is another unusual case of intrageneric variation. Genitalic structures show the following synapomorphous characters, with four or more present in a single species: (1) the gonostylar apex is laterally compressed (Fig. 2B); (2) the gonocoxites have a posteromedial protuberance, which is largely membranous (and thus hard to study by light microscopy) and usually structured in complicated ways (Fig. 2A; see remarks below), and (3) extensive membranous areas ventroposteriorly below the gonostyli (Figs 2A, 4A); (4) the tegmen is provided with a pair of posterolateral processes that are mostly serrate or tubercular (Fig. 15C) and (5) with a pair of elongate apodemes (Fig. 15C; called here the longitudinal apodemes, equal to the ventral processes by Jaschhof \& Jaschhof (2013: fig. 64A); see remarks below); (6) the ejaculatory apodeme is invariably single-pointed and mostly arrow-shaped (Fig. 3C); (7) the posterior edge of the ninth tergite, which is convex (as opposed to concave or bilobed), is mostly provided with megatrichia (Fig. 6D; see remarks below).

\section{Other characters}

As our present study reveals, G. sagittifer is the only species of Glemparon whose postfrons and metepisternum are setose; in all the congeneric species those sclerites are devoid of setae. Therefore, the presence of pronotal and metepisternal setae cannot be regarded as generic characters (see Jaschhof \& Jaschhof 2013). The flagellomeral necks are shorter (Fig. 1H) to several times longer (Fig. 1F) than the nodes. Circumfila, which are present on all but the terminal flagellomeres, have posterior extensions only on the proximal flagellomeres; those extensions, which have different lengths, are either closely adpressed (Fig. 1F) or free-ended (Fig. 1G). In species with generally short extensions, some of the circumfila are simply ring-shaped or sinuous (Fig. 1H). The flagellomeral nodes are completely covered with microtrichia, while the necks are always glabrous. The palpus of $G$. sagittifer was described to have only two to three segments (Jaschhof \& Jaschhof 2013), whereas the conspecific specimen described in the present paper has four segments. The four-segmented condition is found, invariably, in all other species of Glemparon, but both the lengths and shapes of palpal segments are subject to variation, both among different species (see Fig. 1C vs Fig. 1D) and within one and the same species (see Fig. 1D vs Fig. 1E). Pronotal setae are either present or absent. The claws of Glemparon are subrectangular rather than evenly bent, with the distal sections clearly longer than the basal sections, and with one large and two to three small teeth basally. 


\section{Remarks on certain genitalic structures}

The structure called here the posteromedial protuberance possibly indicates the presence of the ninth sternite, which in the basal subfamilies of Cecidomyiidae, including Porricondylinae, is thought to be merged, mostly untraceably, into the ventral gonocoxal bridge (see Jaschhof \& Jaschhof 2013). Protuberances similar to that found in Glemparon are also present here and there in other Dicerurini, such as Dicerura complicata Spungis, 1987; D. adunca Borkent, 1990; and Linnaeomyia hortensis Jaschhof \& Jaschhof, 2015; but only in Glemparon do they have an elaborate structuring. As a matter of fact, Porricondylinae show quite a variety of different modifications at the base of the ventral gonocoxal emargination, many of which might be derived from the ninth sternite; examples are the gonocoxal processes of many Porricondylini (Jaschhof \& Jaschhof 2013: fig. 98B) and different kinds of abnormal vestiture found throughout the subfamily (Jaschhof \& Jaschhof 2013: fig. 155A). In many Glemparon the posteromedial protuberance appears to be connected to either the apex of the ejaculatory apodeme or

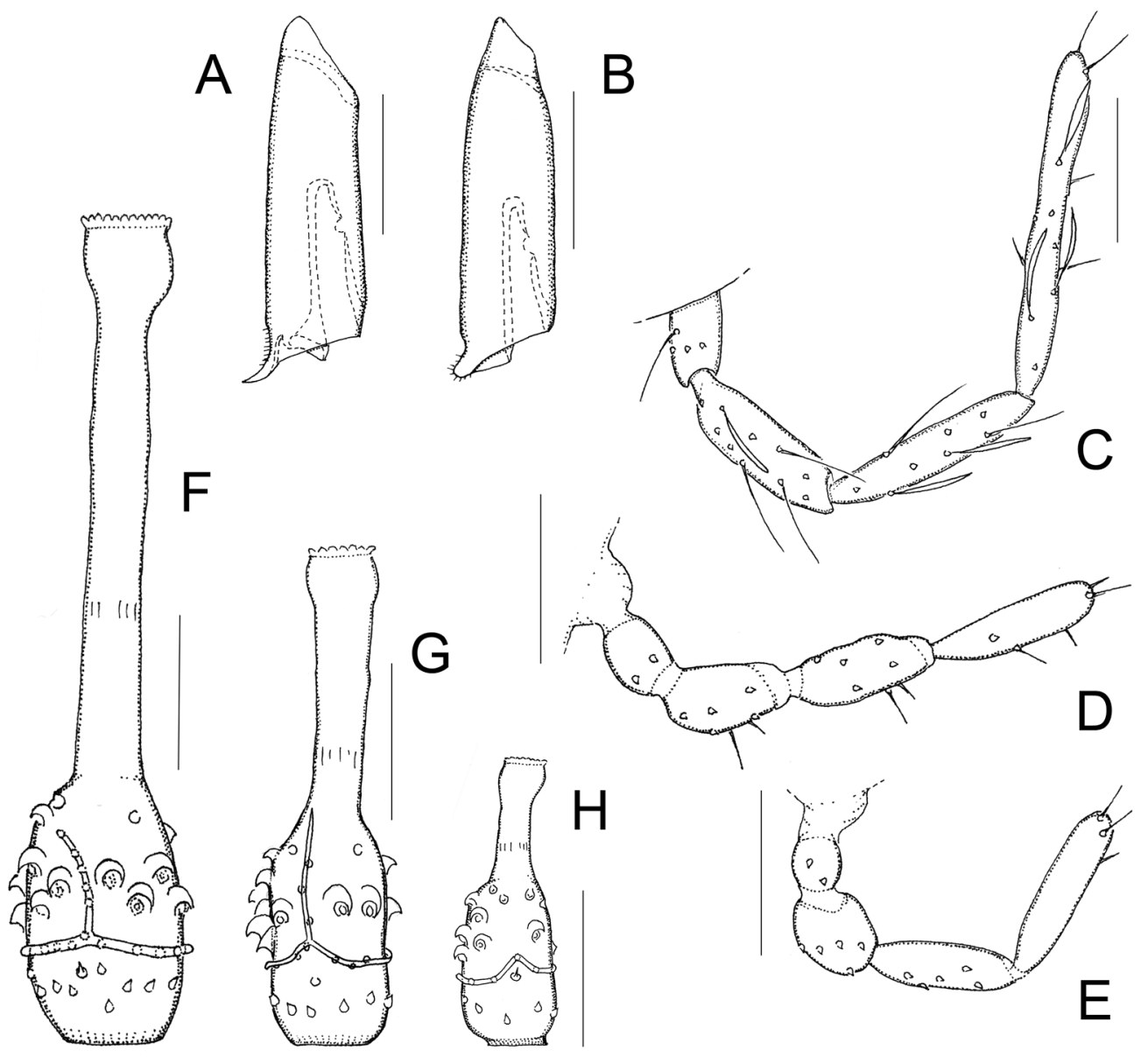

Fig. 1. Morphology of Glemparon spp., $\widehat{\partial} \widehat{\partial}$. A. Basitarsus of foreleg in G. manuka sp. nov., lateral. B. Basitarsus of foreleg in G. warra sp. nov., lateral. C. Palpus of G. orautahi sp. nov., lateral. D. Palpus of G. tomelilla sp. nov., lateral, holotype. E. Palpus of G. tomelilla sp. nov., lateral, paratype. F. Fourth flagellomere of G. manuka sp. nov., lateral. G. Fourth flagellomere of G. orautahi sp. nov., lateral. H. Fourth flagellomere of $G$. tomelilla sp. nov., lateral. Scale bars $=0.05 \mathrm{~mm}$. 
the tegmen, or both; however, their mostly membranous texture and small size makes these connections difficult to study using light microscopy.

The longitudinal apodemes arising from the tegmina of many Glemparon are, to our knowledge, unique within the Dicerurini. They arise, as far as one can discern, from the bases of the posterolateral processes, and either end freely or connect to the inside of the gonocoxal wall. Due to the muscles attached to them, these apodemes are quite conspicuous in our specimens, but one cannot be sure about their visibility in macerated specimens where they possibly become eliminated together with the muscle tissue.

The integumental projections referred to here as megatrichia are conspicuously enlarged microtrichia, which appear to be flattened and bent apically. Megatrichia are unknown to us in other Porricondylinae, including Dicerurini. In Glemparon, they are situated next to ordinary, hair-like microtrichia as well as tubercle-like microtrichia (Fig. 14B), which, within Dicerurini, are found also on the ninth tergite of several Dicerura (e.g., Jaschhof \& Jaschhof 2013: fig. 54A). In Porricondylinae, as in other fungivorous Cecidomyiidae, the phenotypic variation of microtrichia is insufficiently studied.

\section{Relationships to other Dicerurini}

Male morphology suggests that Glemparon is the sister group to Dicerura. In both genera the gonocoxites are provided with ventroposterior lobes (referred to as gonocoxal processes by Jaschhof \& Jaschhof (2013)), which we interpret here as a synapomorphy. The same kind of gonocoxal lobes are present here and there in other Dicerurini, but the few species concerned have genitalic structures that otherwise are very different from that in Glemparon and Dicerura. While there is always a single pair of gonocoxal lobes present in Glemparon, Dicerura may have either one or two pairs. Another derived trait shared by the two genera is the presence of modified microtrichia on the ninth tergite. Apart from large, coarse microtrichia the size of setulae that are commonly found in both genera, many Dicerura have coniform, tubercle-shaped microtrichia, whereas many Glemparon have megatrichia. A third similarity in genitalic characters is that the gonostyli of both groups have exposed, densely microtrichose areas, which in Glemparon are situated at the gonostylar apex but in Dicerura at the gonostylar base ("mediobasal lobe", see Jaschhof \& Jaschhof (2013)). Very few Glemparon have microtrichose bulges at the gonostylar bases, but then in a dorsal, not medial, position. Despite the fact that areas of dense microtrichia are exposed in different positions on the gonostylus - apical in Glemparon, basal to medial in Dicerura their presence might be another indicator of the common ancestry of both genera. Indicative here are the short, blunt-ended bristles situated among the microtrichia in both Glemparon and Dicerura; those bristles are typically located at or near the gonostylar apex (not only in Dicerurini and other Porricondylinae but throughout the fungivorous subfamilies of Cecidomyiidae). It therefore stands to reason that the mediobasal lobe found in Dicerura is actually the gonostylar apex. If so, Glemparon and Dicerura concur in having exposed areas of dense microtrichia intermingled with a few short bristles at the gonostylar apex. To end on another interesting note, two species of Dicerura with structures similar to the gonocoxal posteromedial protuberance found in Glemparon, namely D. complicata and D. adunca, are so aberrant also in other genitalic characters that one might doubt the validity of their current generic placement. However, both species are characterized as true Dicerura by the possession of a bifurcate ejaculatory apodeme, which is the character distinguishing Dicerura from all other Dicerurini, including Glemparon.

\section{Identification of species}

Males of Glemparon can be identified to species using genitalic characters. Each of the 19 species known to date is distinguished by a specific design of either the tegmen or the gonocoxites. Even so, we usually refer to three different structures - usually gonocoxites, gonostylus and tegmen - when diagnosing species, for there is every indication that similar-looking species of Glemparon exist that might be found in the future. Illustrations can describe those structures best and scanning them is, in 
our estimation, the most effective way to identify these taxa. For the same reason we refrain here from presenting a key. The present study, though based on only one to three specimens per species, revealed that non-genitalic characters tend to vary intraspecifically, such as the number of flagellomeres and the outline of palpal segments. Consequently, such characters should be used with caution until the extent of variation is better known.

\section{Species of Glemparon in Sweden}

Glemparon sagittifer Jaschhof, 2013

Fig. 2A-B

Since the first description of this species (Jaschhof \& Jaschhof 2013), only two additional specimens, again males, have been found, one of which is figured here to show some of the genitalic structures in better detail. The gonostylus of G. sagittifer is strongly compressed apically (Fig. 2B), the outline typically found in Glemparon. The gonocoxal posteromedial protuberance possibly bears a pair of dorsally directed processes, of which only the transverse sections are visible in ventral view ( $\downarrow^{1}$, Fig. 2A). One of our specimens has the antennae completely preserved, including 15 flagellomeres. The palpus, which is conspicuously short, has either three or four segments (not either two or three as previously described); pronotal setae are absent (not mentioned in the original description); and the metepisternum has one to three setae (not only one or two as previously described).

\section{Material examined}

SWEDEN: $\widehat{\partial}$, Halland, Halmstad, Gårdshult, Buskastycket, $56.41^{\circ} \mathrm{N}, 13.91^{\circ} \mathrm{E}, 3-25$ May 2005, hay meadow, Malaise trap, Swedish Malaise Trap Project leg. (trap 35, collecting event 1786) (NHRS,

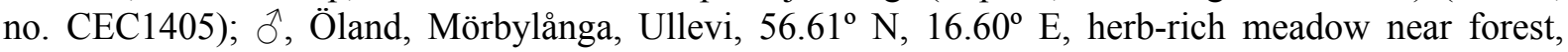
8 Apr.-9 May 2016, Malaise trap, M. \& C. Jaschhof leg. (SDEI, no. CEC1429).

\section{Remark on occurrence}

The specimen studied here from Halland was collected by the same trap (but on an earlier date) that captured the paratype of G. sagittifer (see Jaschhof \& Jaschhof 2013).

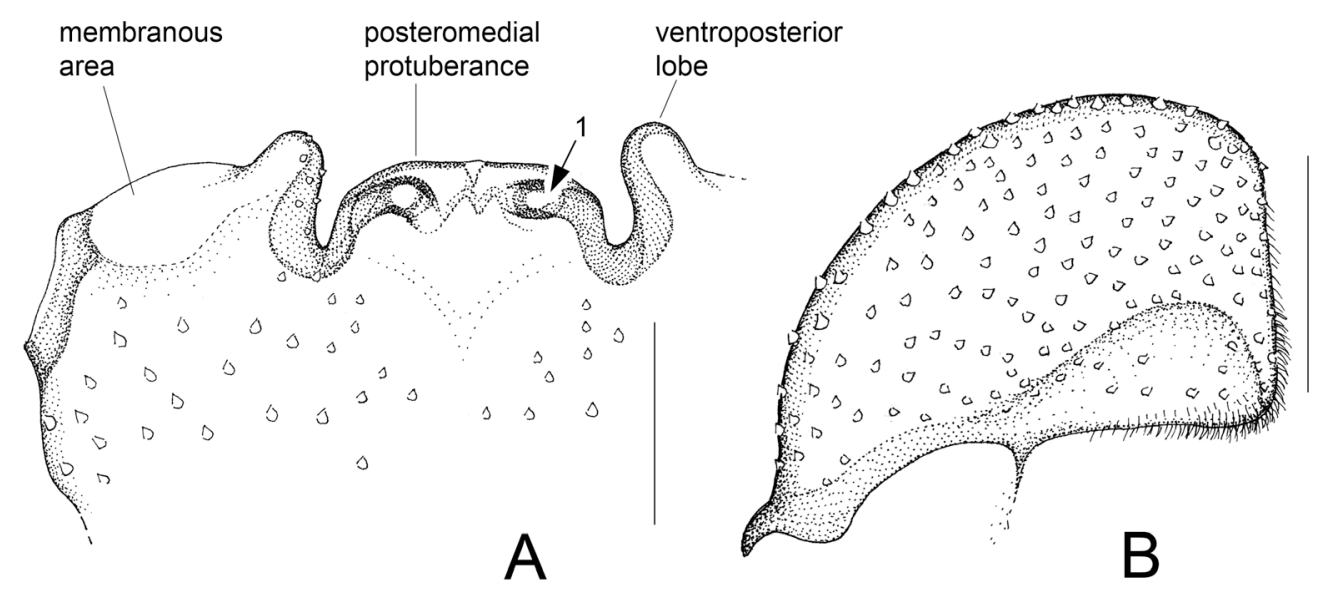

Fig. 2. Glemparon sagittifer Jaschhof, 2013, ô. A. Gonocoxites, ventroposterior. B. Gonostylus, ventral. Scale bars $=0.05 \mathrm{~mm}$. The numbered arrow indicates a diagnostic character (see description). 


\section{Glemparon tomelilla sp. nov. urn:1sid:zoobank.org:act:3C0D5E2F-A9F4-4E11-9490-B5E79432B502}

Figs 1D-E, H, 3A-D

\section{Diagnosis}

The ventroposterior edge of the gonocoxites has a V-shaped emargination flanked by subtriangular lobes of moderate size ( $\downarrow^{1}$, Fig. 3A); the posteromedial protuberance has a slightly sinuous edge and a pair of ovate substructures, whose outline may remind one of eyeglasses ( $\downarrow^{2}$, Fig. 3A). The roughly $\mathrm{H}$-shaped tegmen is provided with a pair of posterolateral processes whose spike-bearing apices are bent ventrolaterally ( $\downarrow^{3}$, Fig. 3D). The vestiture of the ninth tergite (Fig. 3A) consists of normal setae and microtrichia; megatrichia are absent.

\section{Etymology}

The specific epithet refers to Tomelilla, a small town in Sweden's province Skåne, where the holotype specimen was collected.

\section{Material examined}

\section{Holotype}

SWEDEN: §ె, Skåne, Tomelilla, Drakamöllan, grassy heathland, 29 Apr.-19 May 2004, Malaise trap, Swedish Malaise Trap Project leg. (trap 38, collecting event 599) (NHRS, no. CEC1406).

\section{Paratype}

SWEDEN: đ̄, Öland, Borgholm, Rönnerum-Abbantorp Nature Reserve, small bushy fen within broadleaf forest, , 16 Jul.-21 Aug. 2015, Malaise trap, M. and C. Jaschhof legs (SDEI, no. CEC1407).

\section{Differential diagnosis}

Glemparon tomelilla sp. nov. differs from G. sagittifer, the only congener in the Palearctic, in the outline of the posterior gonocoxal edge, the structuring of the tegmen, and the more slender gonostylus. Furthermore, G. sagittifer has metepimeral setae, which are missing in G. tomelilla sp. nov. A species with genitalic structures generally similar to that of G. tomelilla sp. nov. is G. warra sp. nov. from Tasmania (Fig. 20A-D).

\section{Other characters}

BODY SIZE. 1.6-1.7 mm.

HEAD. Eye bridge 2-3 ommatidia long dorsally. Flagellomeres 14; apical flagellomere simple (holotype) or obviously merged of two bodies (paratype); neck of fourth flagellomere 0.8 times the node (Fig. $1 \mathrm{H}$ ). Palpus shorter than head height, 4 setae-bearing segments; first segment smallest of all; second segment slightly swollen, which is more pronounced in the paratype (Fig. 1E) compared with the holotype (Fig. 1D).

Thorax. Pronotal setae absent.

WING. Length/width ratio 2.8. Rs long, one third of apicR .

LEgs. Basitarsal spines absent.

TERMINALIA. Gonocoxites with narrow, unsetose, separate section ventrobasally; medial bridges clearly convex, in close distance to each other (Fig. 3A). Gonostylus 2.5 times longer than broad; densely setose 
except the concave portions medially and the somewhat angular-shaped, densely microtrichose apex (Fig. 3B). Ejaculatory apodeme with large, membranous, arrow-shaped apex (Fig. 3C).

\section{Distribution and phenology}

This species is known from two locations in southern Sweden, where only two specimens were obtained as a result of extensive Malaise trapping all over Sweden by both the Swedish Malaise Trap Project and ourselves for several years. A common feature of the two collecting sites is that grasses predominate in the ground cover, with one of the sites being markedly dry, the other rather swampy. Specimens were collected during the main vegetation period in May-August.

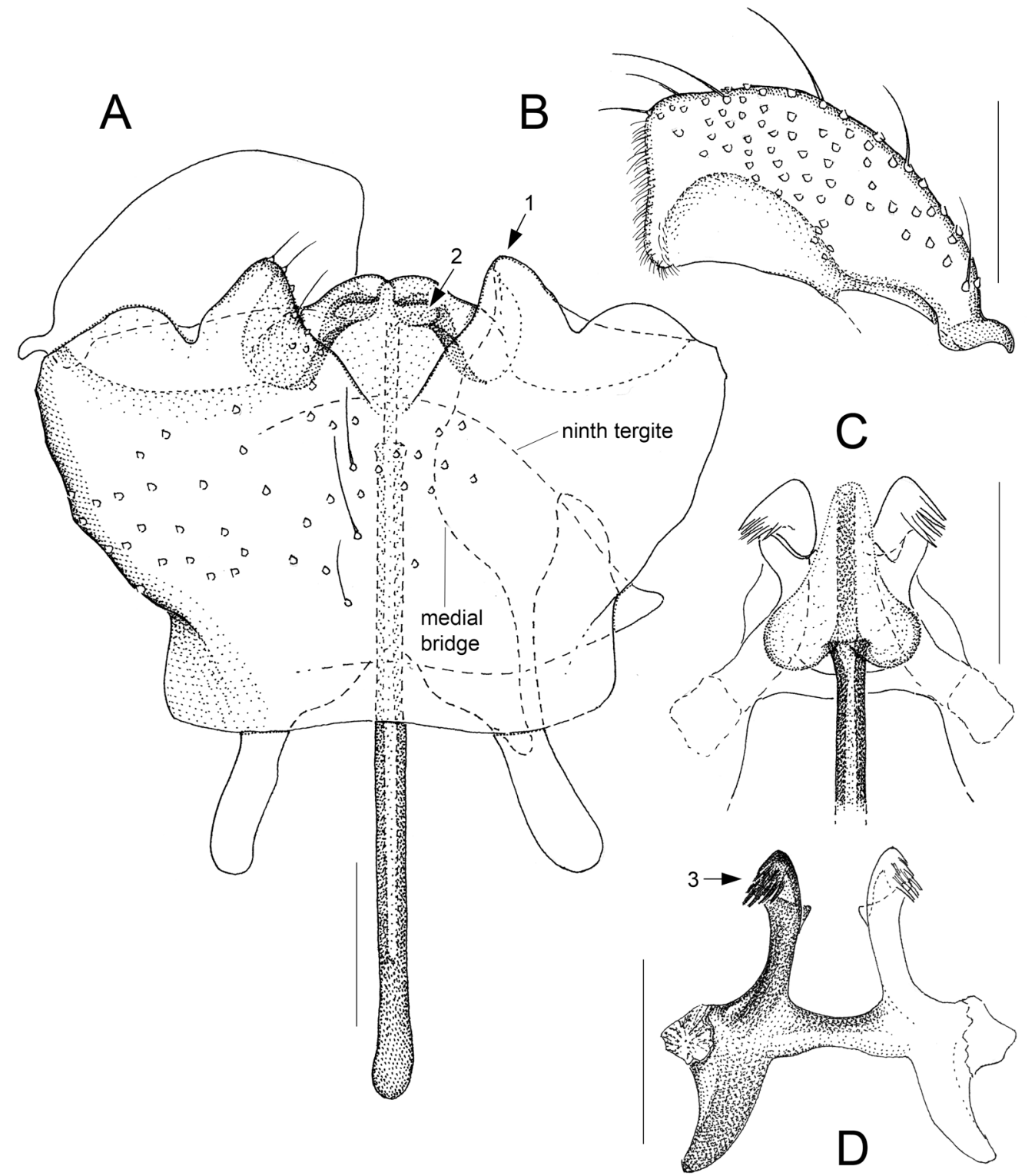

Fig. 3. Glemparon tomelilla sp. nov., $\widehat{\jmath} \widehat{\jmath}$. A-C. Holotype (NHRS, no. CEC1406). A. Genitalia, ventral. B. Gonostylus, ventral. C. Apex of ejaculatory apodeme, tegmen indicated, ventral. D. Tegmen, ventral, paratype (NHRS, no. CEC1407). Scale bars $=0.05 \mathrm{~mm}$. Numbered arrows indicate diagnostic characters (see Diagnosis). 


\section{Species of Glemparon in New Zealand}

Glemparon aotearoa sp. nov.

urn:1sid:zoobank.org:act:924A6DCA-64AC-4686-BB45-EFE7013FD2CC

Fig. $4 \mathrm{~A}-\mathrm{C}$

\section{Diagnosis}

A peculiarity of $G$. aotearoa sp. nov. is the markedly bulbous gonostylus ( $\downarrow^{1}$, Fig. 4B). Of the gonocoxites, the membranous areas below the gonostyli are conspicuously large ( $\downarrow^{2}$, Fig. 4A), the small, subrectangular, ventral emargination $\left(\downarrow^{3}\right.$, Fig. 4A) is flanked by subtriangular lobes of moderate size, and the posteromedial protuberance is inconspicuous. The posterolateral processes of the tegmen have serrate edges, including one larger, bent sawtooth anteriorly ( $\downarrow^{4}$, Fig. $\left.4 \mathrm{C}\right)$.

\section{Etymology}

The specific epithet, aotearoa, is the Maori name for the country of New Zealand, meaning "land of the long white cloud".

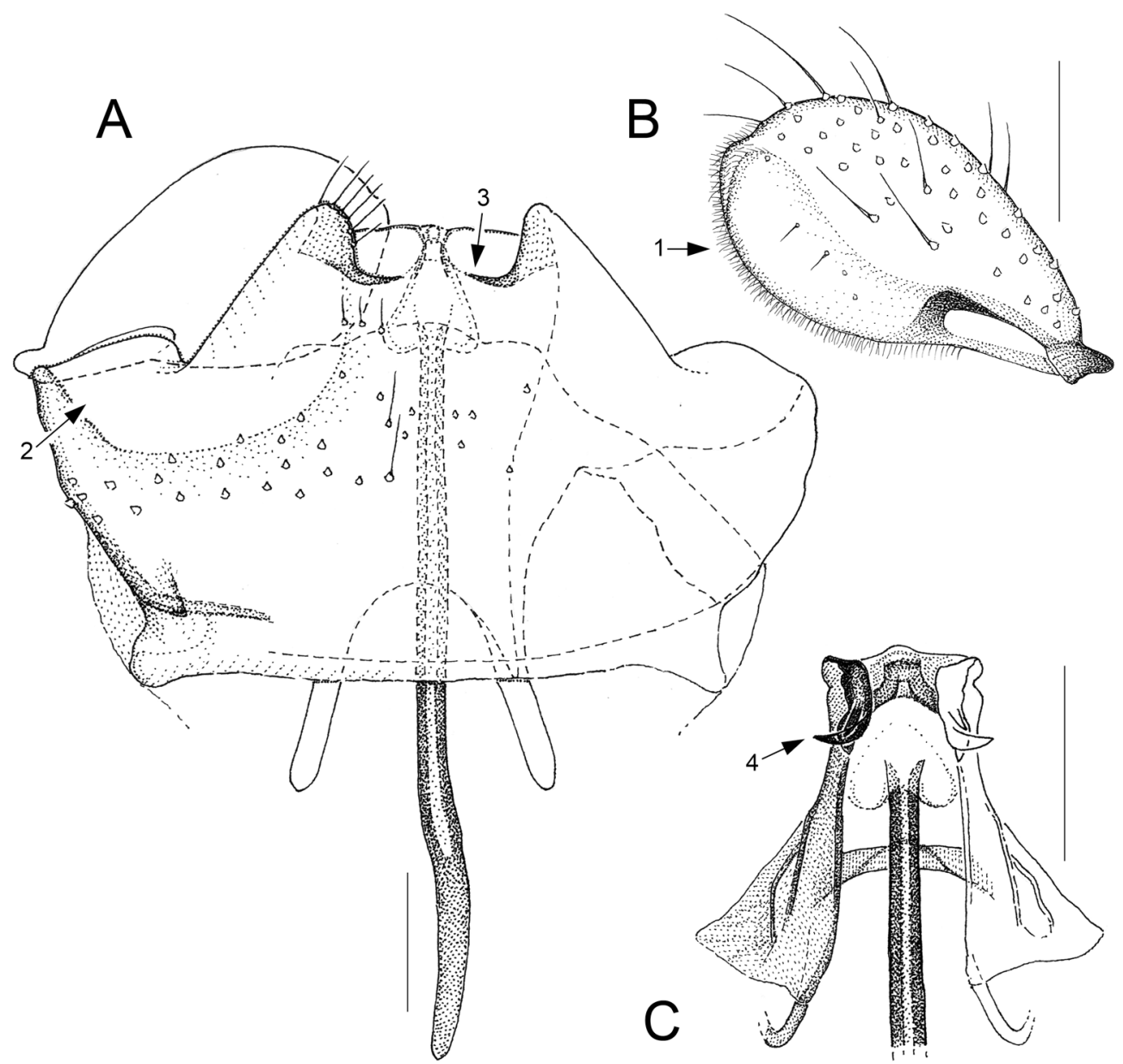

Fig. 4. Glemparon aotearoa sp. nov., holotype, $\widehat{\partial}$ (NZAC, no. CEC1419). A. Genitalia, ventral. B. Gonostylus, ventral. C. Apex of ejaculatory apodeme and tegmen, ventral. Scale bars $=0.05 \mathrm{~mm}$. Numbered arrows indicate diagnostic characters (see Diagnosis). 


\section{Material examined}

\section{Holotype}

NEW ZEALAND: §̊, South Island, Tasman, Nelson Lakes National Park, Lake Rotoroa, $450 \mathrm{~m}$ a.s.l., 15 Jan. 2001 mixed podocarp/southern beech forest, Malaise trap, Department of Conservation St. Arnaud leg.(NZAC, no. CEC1419).

\section{Other characters}

BODY SIZE. $2.0 \mathrm{~mm}$.

HEAD. Eye bridge 2 ommatidia long dorsally. Flagellomeres 15; apical flagellomere obviously merged of two bodies; neck of fourth flagellomere 1.1 times the node. Palpus shorter than head height, 4 setaebearing segments.

Thorax. Pronotal setae present.

WING. Length/width ratio 3.1. Rs short, one fifth of apicR .

LEGs. Basitarsal spines present.

Terminalia. Posterior edge of ninth tergite with large, hair-like microtrichia. Gonocoxites with narrow, unsetose, separate section ventrobasally (Fig. 4A). Gonostylus twice longer than broad; outside densely setose; inside with dense, fine pubescence, and very few fine setulae (Fig. 4B). Apex of ejaculatory apodeme small, membranous, arrow-shaped (Fig. 4C).

\section{Distribution and phenology}

The single specimen known of G. aotearoa sp. nov. was Malaise trapped at the height of summer in an old-growth native forest in the north of New Zealand's South Island. The same trap collected simultaneously four other species of Glemparon: G. birhojohmi sp. nov., G. cervus sp. nov., G. rotoroa sp. nov., and G. tewaipounamu sp. nov.

Glemparon birhojohmi sp. nov. urn:1sid:zoobank.org:act:375CA647-4FAD-4CF1-86AD-46509ADF74C9

Fig. 5A-C

\section{Diagnosis}

The following combination of genitalic characters is characteristic of G. birhojohmi sp. nov.: the gonostylus, which is twice longer than broad, is slightly constricted subbasally ( $\downarrow^{1}$, Fig. 5A); the gonocoxal posteromedial protuberance, which is flanked by small, subtriangular lobes, has a weakly sclerotized, T-shaped process that projects ventrally ( $\downarrow^{2}$, Fig. 5A); below the protuberance is an assemblage of conspicuously dense setae ( $\downarrow^{3}$, Fig. 5A); and the medial bridges have mostly setae of various sizes rather than microtrichia.

\section{Etymology}

In naming this new species birhojohmi, we honor Birgit Rhode and John Mitchell, of Papakura, Auckland, New Zealand. Birgit and John, both gifted with an artistic, creative disposition, have been supportive of our taxonomic work for many years. The name should be treated as a noun in apposition. 


\section{Material examined}

\section{Holotype}

NEW ZEALAND: $\widehat{\jmath}$, South Island, Tasman, Nelson Lakes National Park, Lake Rotoroa, $450 \mathrm{~m}$ a.s.l., 15 Jan. 2001, mixed podocarp / southern beech forest, Malaise trap, Department of Conservation St. Arnaud leg. (NZAC, no. CEC1426).

\section{Paratype}

NEW ZEALAND: $\widehat{\jmath}$, same data as for holotype but 4 Apr. 2001 (NZAC, no. CEC1427).

\section{Differential diagnosis}

Glemparon nativitas sp. nov., a broadly similar species found in Stewart Island, differs in broader gonostyli (Fig. 9B) and details of the tegmen (Fig. 9C).

\section{Other characters}

BODY SIZE. $2.2 \mathrm{~mm}$.

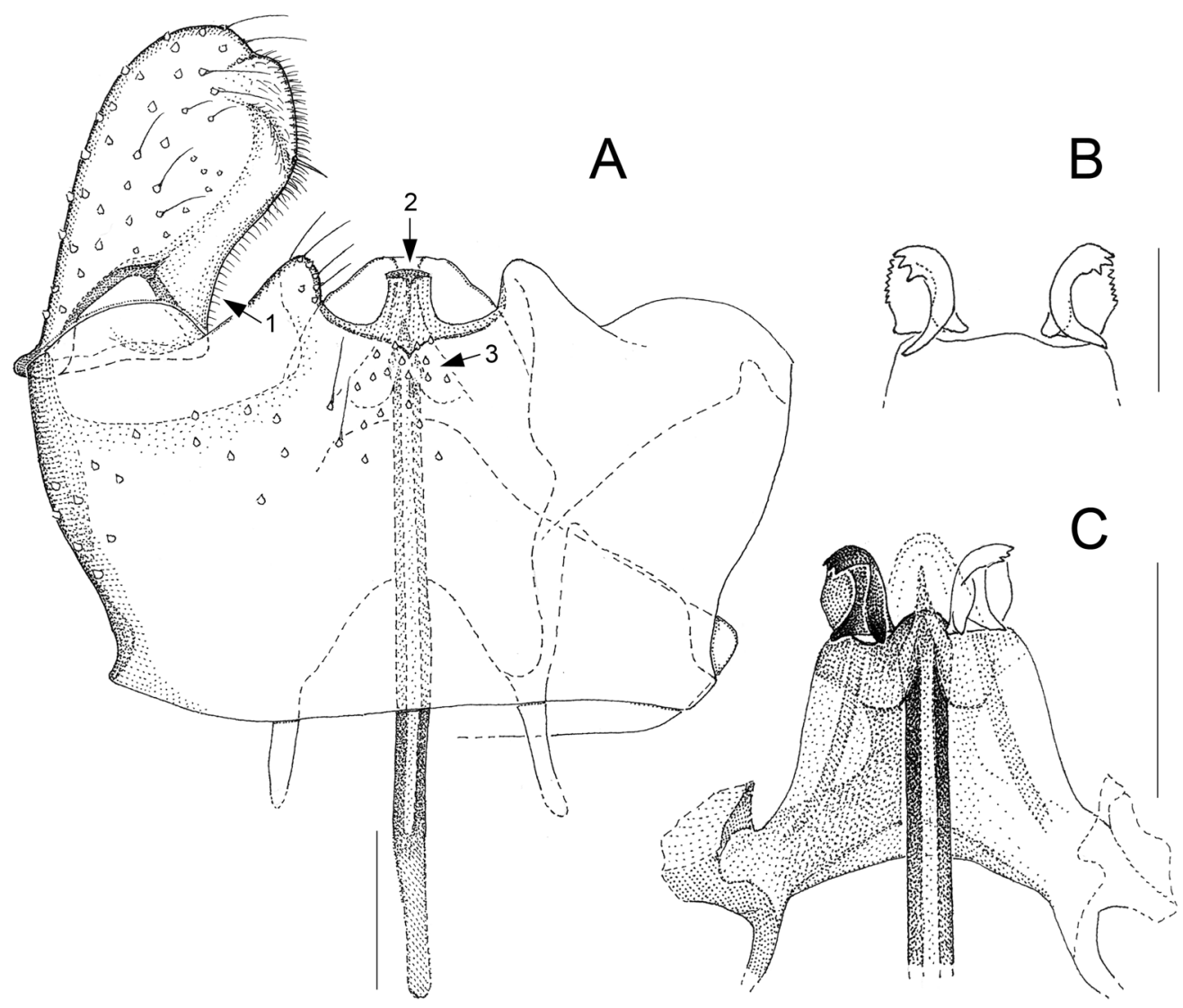

Fig. 5. Glemparon birhojohmi sp. nov., $\widehat{\partial} \widehat{\partial}$. A. Genitalia, ventral, holotype (NZAC, no. CEC1426). B. Tegminal processes, ventral, paratype (NZAC, no. CEC1427). C. Apex of ejaculatory apodeme and tegmen, ventral, holotype. Scale bars: A, C $=0.05 \mathrm{~mm}$; B $=0.025 \mathrm{~mm}$. Numbered arrows indicate diagnostic characters (see Diagnosis). 
HEAD. Eye bridge 2-3 ommatidia long dorsally. Nine flagellomeres retained; neck of fourth flagellomere 1.8 times the node. Palpus slightly shorter than head height, 4 setae-bearing segments, apical segment conspicuously long, twice longer than penultimate segment.

THORAX. Pronotal setae present.

WING. Length/width ratio 3.4. Rs short, one seventh of apicR .

LEGS. Basitarsal spines present.

Terminalia. Posterior edge of ninth tergite with dense megatrichia. Gonocoxites without setae on narrowed ventrobasal portion (Fig. 5A). Gonostylar apex with slight depression above densely microtrichose portion medially (Fig. 5A). Sclerotized portion of ejaculatory apodeme pointed apically, covered by membranous cap (Fig. 5C). Posterolateral processes of tegmen with serrate edges, including 1-2 larger sawteeth anteriorly (Fig. 5B-C; see remark on variation).

\title{
Remark on variation
}

The paratype (Fig. 5B) differs slightly from the holotype (Fig. 5C) in that the tooth situated most anteriorly on the tegminal processes is conspicuously large and bent. These teeth are apparently somewhat variable in shape, size, and relative position.

\section{Distribution and phenology}

See G. aotearoa sp. nov. The paratype of G. birhojohmi sp. nov. was captured almost three months later than the holotype at the same site, indicating a long adult flight period in this species.

\author{
Glemparon cervus sp. nov. \\ urn:1sid:zoobank.org:act:B186CEF1-8C4B-4FBF-98A3-C3A07A7EFC41
}

Fig. 6A-D

\section{Diagnosis}

The elongate gonostylus is markedly wedge-shaped all along the medial edge (Fig. 6B). The gonocoxites have conspicuously large membranous areas below the gonostyli ( $\downarrow^{1}$, Fig. 6A); the posteromedial protuberance is provided with a pointed, sclerotized process that projects ventrally ( $\downarrow^{2}$, Fig. 6A). The tegminal processes, with their multiple points, are reminiscent of deers' antlers ( $\downarrow^{3}$, Fig. 6C).

\section{Etymology}

The specific epithet, cervus, is the Latin word for deer, an allusion to the antler-shaped tegminal processes found in this species. The name is a noun in apposition.

\section{Material examined}

\section{Holotype}

NEW ZEALAND: $\widehat{\jmath}$, South Island, Tasman, Nelson Lakes National Park, Lake Rotoroa, $450 \mathrm{~m}$ a.s.l., 15 Jan. 2001, mixed podocarp/southern beech forest, Malaise trap, Department of Conservation St. Arnaud leg. (NZAC, no. CEC1414).

\section{Differential diagnosis}

A remarkably similar species found co-occurring with G. cervus sp. nov. is G. tewaipounamu sp. nov. It differs in both the gonostylus, which has a pubescent bulge dorsobasally (Fig. 16B), and several details in the gonocoxites (Fig. 16A) and the tegmen (Fig. 16C). The posteromedial protuberance provided with 
a sclerotized, pointed process is a character that G. cervus sp. nov. shares with G. orautahi sp. nov. (see below), but otherwise these two species are rather dissimilar.

\section{Other characters}

BODY SIZE. $1.7 \mathrm{~mm}$.

HEAD. Eye bridge 2-3 ommatidia long dorsally. Nine flagellomeres retained; neck of fourth flagellomere 1.3 times the node. Palpus slightly shorter than head height, 4 setae-bearing segments, apical segment longest of all.

THORAX. Pronotal setae present.

WING. Length/width ratio 3.3. Rs short, one sixth of apicR .

LeGs. Basitarsal spines absent.

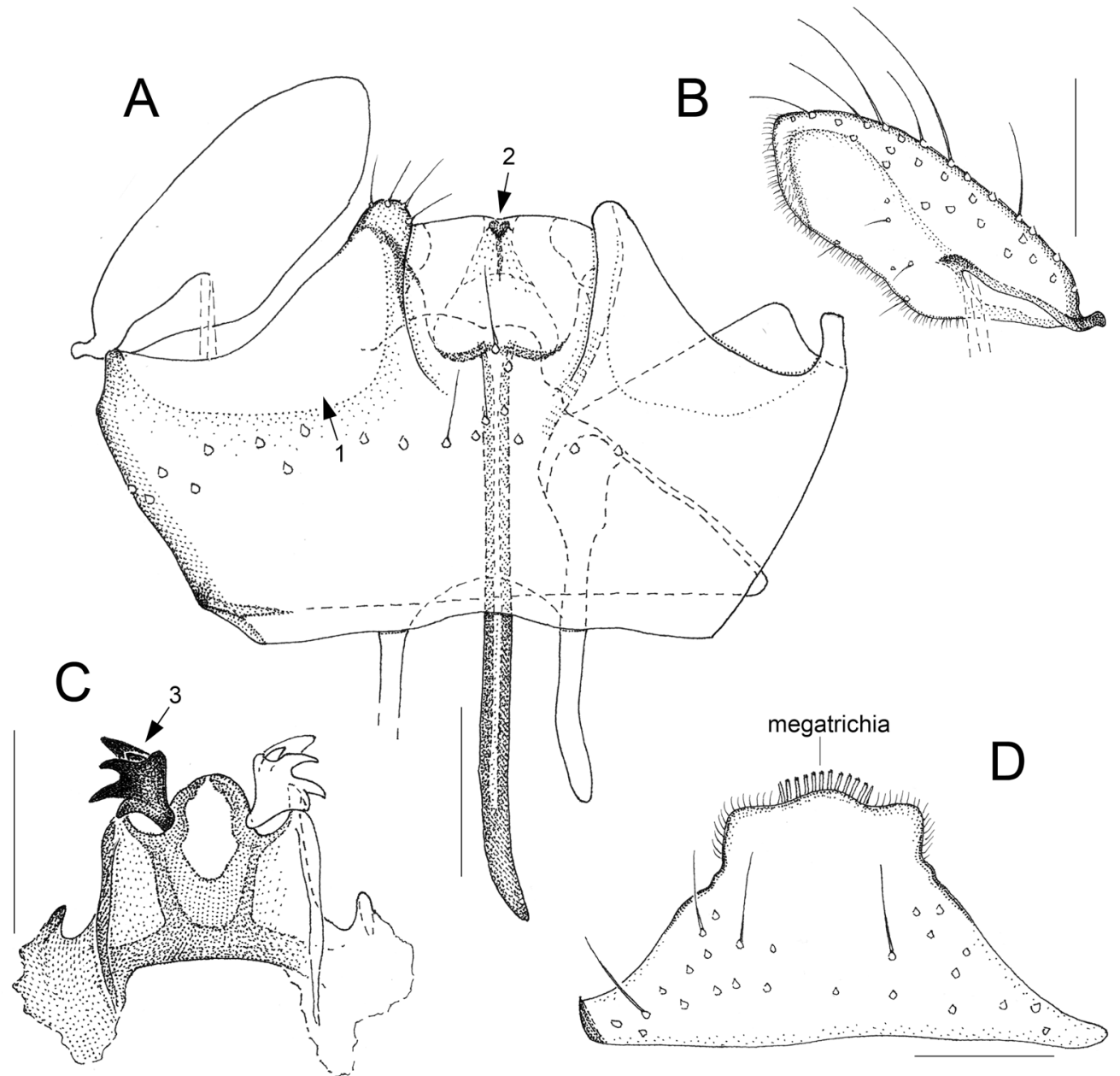

Fig. 6. Glemparon cervus sp. nov., holotype, $\hat{o}$ (NZAC, no. CEC1414). A. Genitalia, ventral. B. Gonostylus, ventral. C. Tegmen, ventral. D. Ninth tergite, dorsal. Scale bars $=0.05 \mathrm{~mm}$. Numbered arrows indicate diagnostic characters (see Diagnosis). 
Terminalia. Posterior edge of ninth tergite slightly three-lobed, central lobe rounded, with about 12 megatrichia, flanked by angular-shaped, densely microtrichose side lobes (Fig. 6C). Gonocoxites (Fig. 6A): ventral emargination as broad as long, poorly delineated basally, flanked by rather large, subtriangular lobes; ventral setae sparse. Gonostylus parallel-sided, 3.0 times as long as broad (Fig. 6B). Apex of ejaculatory apodeme membranous, arrow-shaped (Fig. 6A). Tegmen with conspicuous pattern of sclerotization (Fig. 6C).

\section{Distribution and phenology}

See G. aotearoa sp. nov.

Glemparon didhami sp. nov.

urn:1sid:zoobank.org:act:D99AB209-77DF-46E7-BE78-22DDFC312B79

Fig. 7A-B

\section{Diagnosis}

Characters specific to G. didhami sp. nov. are the gonocoxites, whose posteromedial protuberance has a distinctive pattern of sclerotization $\left(\downarrow^{1}\right.$, Fig. $\left.7 \mathrm{~A}\right)$; the roundish lobes flanking the protuberance are

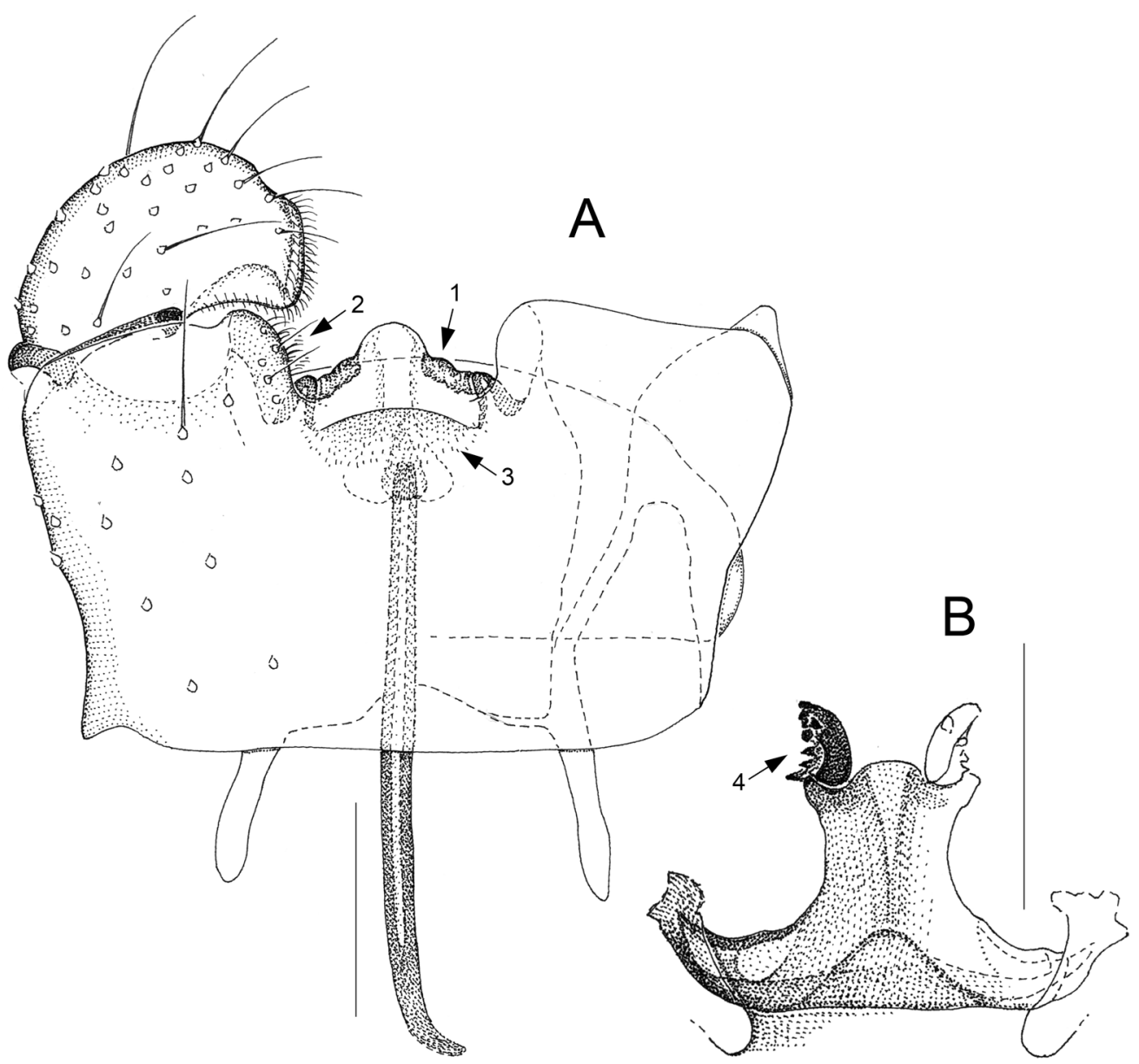

Fig. 7. Glemparon didhami sp. nov., holotype, ơ (NZAC, no. CEC1422). A. Genitalia, ventral. B. Tegmen, ventral. Scale bars $=0.05 \mathrm{~mm}$. Numbered arrows indicate diagnostic characters (see Diagnosis). 
inconspicuous ( $\downarrow^{2}$, Fig. 7A); the ventral emargination is sclerotized basally ( $\downarrow^{3}$, Fig. 7A); and ventral setae are reduced to the lateral portions. The tegminal processes have multiple small tubercles and points, which are harder to discern than Figure 7B $\left(\downarrow^{4}\right)$ suggests. The ninth tergite has a broadly rounded posterior edge, whose vestiture is of ordinary microtrichia and setae of various sizes.

\section{Etymology}

This new species is named after Raphael K. Didham, ecologist at The University of Western Australia, Perth, who collected several of the specimens studied here, including the holotype of G. didhami sp. nov.

\section{Material examined}

\section{Holotype}

NEW ZEALAND: $\widehat{\jmath}$, Stewart Island, Christmas Village Hut, $46.74^{\circ} \mathrm{S}, 167.97^{\circ} \mathrm{E}, 18$ Jan. 2000, Malaise trap, R.K. Didham leg. (NZAC, no. CEC1422).

\section{Other characters}

BODY SIZE. $1.5 \mathrm{~mm}$.

HEAD. Eye bridge 1-2 ommatidia long dorsally. Six flagellomeres retained; neck of fourth flagellomere 1.3 times the node. Palpus shorter than head height, 4 setae-bearing segments, apical segment longest of all.

THORAX. Pronotal setae present.

WING. Length/width ratio 3.1. Rs short, one sixth of apicR .

LEGS. Basitarsal spines absent.

TERMINALIA. Gonocoxites: membranous areas below gonostylus small (Fig. 7A). Gonostylus twice longer than broad, with slight depression above densely microtrichose apex (Fig. 7A). Sclerotized portion of ejaculatory apodeme slightly thickened apically, covered by membranous cap (Fig. 7A).

\section{Distribution and phenology}

The only specimen known of $G$. didhami sp. nov. was Malaise trapped at the height of summer in the native bush of Stewart Island, the smallest and southernmost of New Zealand's main islands. The same Malaise trap collected simultaneously two other species of Glemparon: G. nativitas sp. nov. and G. rakiura sp. nov.

Glemparon kaikoura sp. nov. urn:1sid:zoobank.org:act:9D30A751-629B-402F-BC40-76ACD0DE24FB

Fig. $8 \mathrm{~A}-\mathrm{C}$

\section{Diagnosis}

The ventroposterior edge of the gonocoxites, formed by a pair of rounded lobes flanking a shallow emargination, is sinuous ( $\downarrow^{1}$, Fig. 8A); the posteromedial protuberance is small and unmodified $\left(\downarrow^{2}\right.$, Fig. 8A). The posterolateral processes of the tegmen have a complicated structuring, including a flat, subtriangular portion pointing ventrolaterally ( $\downarrow^{3}$, Fig. $\left.8 \mathrm{C}\right)$ and a flat, spoon-shaped portion pointing dorsomedially ( $\downarrow^{4}$, Fig. 8C). The elongate gonostylus is markedly wedge-shaped along the apical and medial edges (Fig. 8B). 


\section{Etymology}

The specific epithet refers to Kaikoura, a small coastal town on New Zealand's South Island, where the holotype specimen was collected.

\section{Material examined}

\section{Holotype}

NEW ZEALAND: $\widehat{\jmath}$, South Island, Kaikoura, Blue Duck Reserve, 300-400 m a.s.1., 12 May-9 Jun. 2001, young mixed podocarp/southern beech forest, Malaise trap, M. and C. Jaschhof leg. (NZAC, no. CEC1411).

\section{Other characters}

BoDy SIZE. $2.0 \mathrm{~mm}$.

HEAD. Eye bridge $0-1$ ommatidium long dorsally. Flagellomeres 18; apical flagellomere merged of two bodies; neck of fourth flagellomere 1.8 times the node. Palpus almost as long as head height, 4 setaebearing segments, apical segment longest of all.

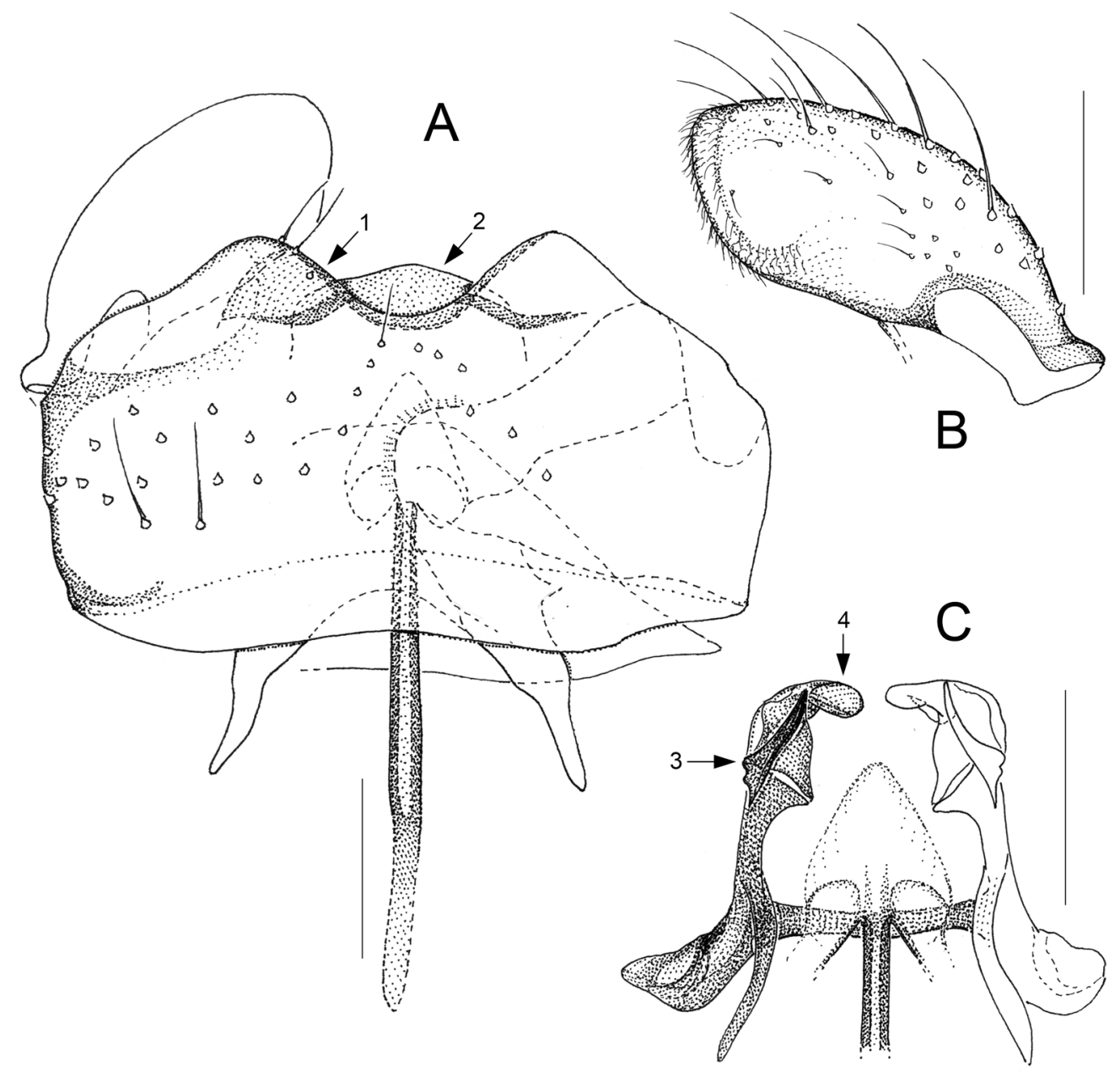

Fig. 8. Glemparon kaikoura sp. nov., holotype, $\widehat{o}$ (NZAC, no. CEC1411). A. Genitalia, ventral. B. Gonostylus, ventral. C. Apex of ejaculatory apodeme and tegmen, ventral. Scale bars $=0.05 \mathrm{~mm}$. Numbered arrows indicate diagnostic characters (see Diagnosis). 
Thorax. Pronotal setae present.

WING. Length/width ratio 2.8. Rs short, one fifth of apicR .

LEGS. Basitarsal spines absent.

TeRminALIA. Gonocoxites: ventrobasal portion unsetose, membranous rather than sclerotized; medial bridges densely microtrichose, strongly protruding, almost in touch with each other (Fig. 8A). Gonostylus 2.5 times longer than broad, parallel-sided, slightly bent (Fig. 8B). Apex of ejaculatory apodeme membranous, arrow-shaped (Fig. 8C).

\section{Distribution and phenology}

The holotype of G. kaikoura sp. nov. was collected at the end of autumn in a patch of regenerating native bush on the east coast of New Zealand's South Island.

Glemparon nativitas sp. nov.

urn:1sid:zoobank.org:act:BECAA06E-A080-438D-B6EB-C0E9D3B35C07

Fig. 9A-C

\section{Diagnosis}

The gonostylar base in G. nativitas sp. nov. is broader than in any other species of Glemparon ( $\downarrow^{1}$, Fig. 9B). The setae on the ventral gonocoxal surface form a cross-shape (Fig. 9A); the medial bridges are densely microtrichose ( $\downarrow^{2}$, Fig. 9A); and the posteromedial protuberance has a T-shaped, sclerotized process that projects ventrally ( $\downarrow^{3}$, Fig. 9A). The tegminal processes have a serrate posterior edge, with the largest sawteeth situated ventrally $\left(\downarrow^{4}\right.$, Fig. 9C).

\section{Etymology}

The specific epithet is a Latin noun in apposition meaning Christmas, an allusion to Christmas Village Hut on Stewart Island, the type locality.

\section{Material examined}

\section{Holotype}

NEW ZEALAND: $\curvearrowright$, Stewart Island, Christmas Village Hut, $46.74^{\circ} \mathrm{S}, 167.97^{\circ}$ E, 18 Jan. 2000, Malaise trap, R.K. Didham leg. (NZAC, no. CEC1421).

\section{Other characters}

BODY SIZE. $1.9 \mathrm{~mm}$.

HEAD. Eye bridge 1-2 ommatidia long dorsally. Flagellomeres 14; neck of fourth flagellomere 1.5 times the node. Palpus slightly shorter than head height, 4 setae-bearing segments, apical segment longest of all.

THORAX. Pronotal setae absent.

WING. Length/width ratio 3.2. Rs short, one sixth of apicR .

LeGs. Basitarsal spines absent. 
Terminalia. Posterior edge of ninth tergite slightly three-lobed, central lobe rounded, with about 10 megatrichia, flanked by angular-shaped, densely microtrichose side lobes (Fig. 9A). Ventroposterior lobes of gonocoxites small, rounded (Fig. 9A). Gonostylus twice longer than broad, with slight depression above densely microtrichose apex (Fig. 9B). Apex of ejaculatory apodeme membranous, arrow-shaped. Tegmen with characteristic pattern of sclerotization medially (Fig. 9C).

\section{Distribution and phenology}

See G. didhami sp. nov.

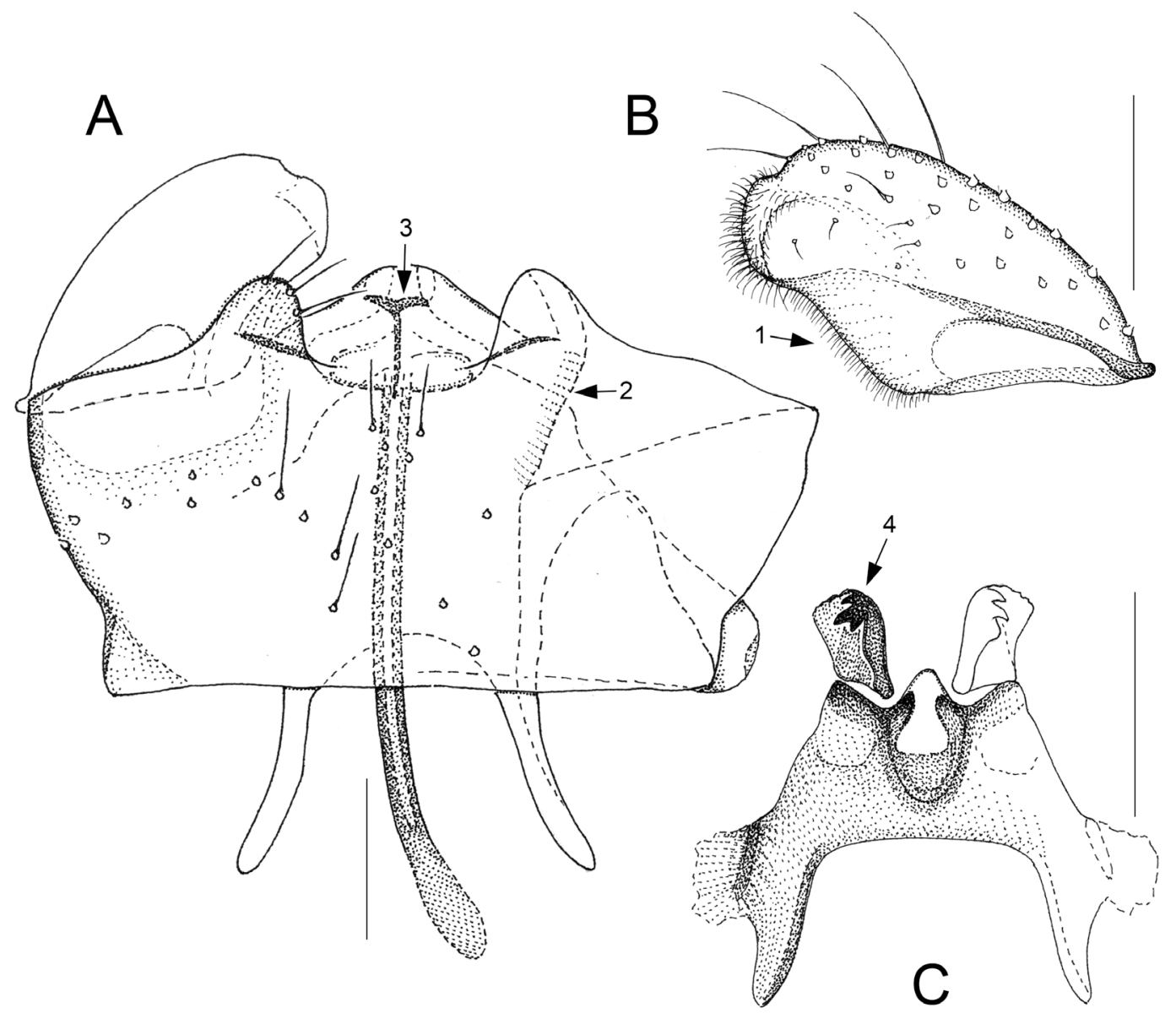

Fig. 9. Glemparon nativitas sp. nov., holotype, ô (NZAC, no. CEC1421). A. Genitalia, ventral. B. Gonostylus, ventral. C. Tegmen, ventral. Scale bars $=0.05 \mathrm{~mm}$. Numbered arrows indicate diagnostic characters (see Diagnosis). 
Glemparon orautahi sp. nov.

urn:1sid:zoobank.org:act:70016DA0-BDA1-4D22-AD1A-DBE2D5E29DAD

Figs 1C, G, 10A-D

\section{Diagnosis}

Genitalic structures characteristic of G. orautahi sp. nov. are the gonostylus, which is massive apically and strongly bent at the midlength $\left(\downarrow^{1}\right.$, Fig. 10C); the tegminal processes, which consist of a strongly sclerotized, tuberculous portion posteriorly and a weakly sclerotized, spiny portion laterally $\left(\downarrow^{2}\right.$, Fig. 10D); and the posteromedial protuberance, whose pointed, sclerotized process projects ventrally ( $\downarrow^{3}$, Fig. 10B).

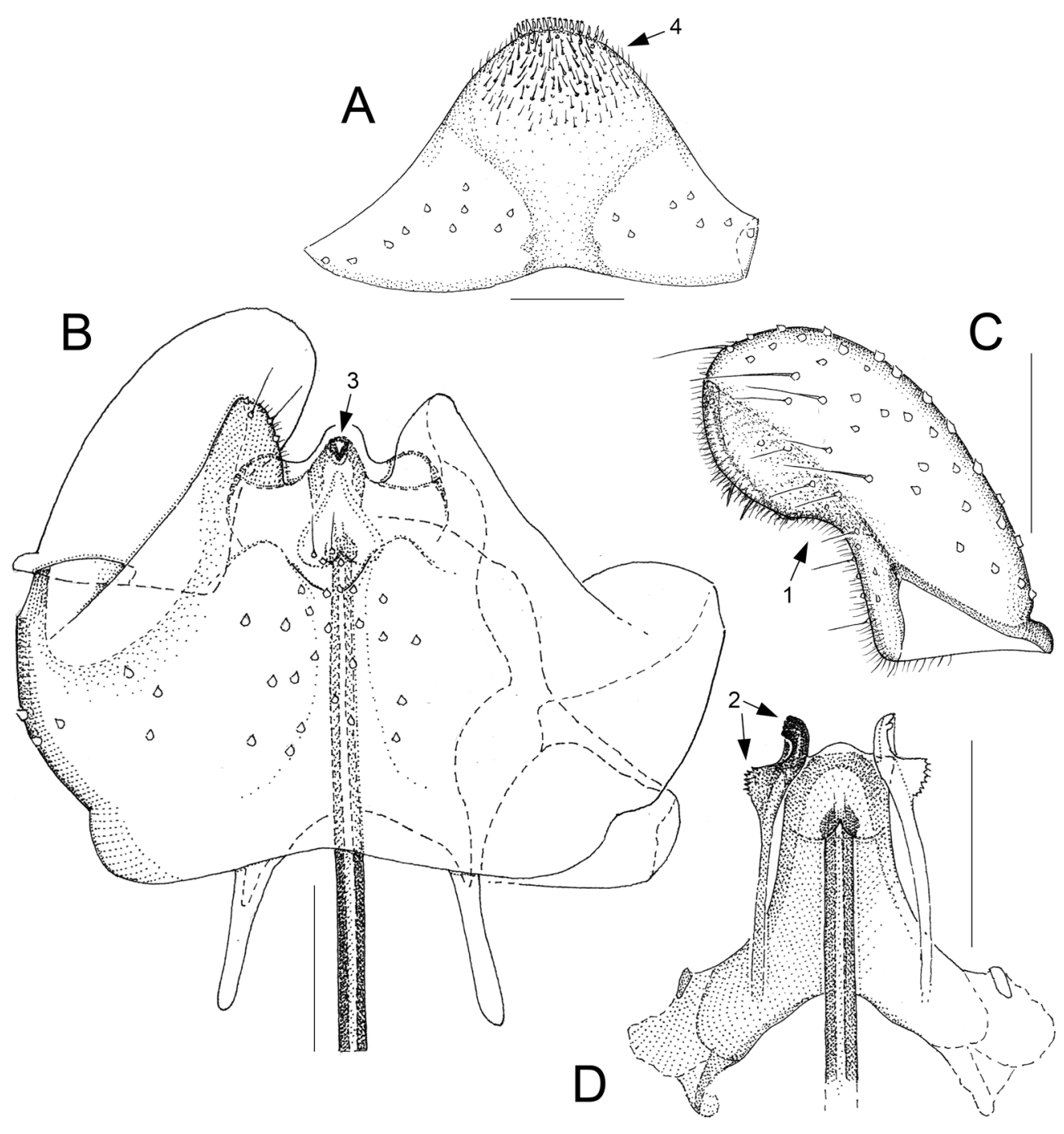

Fig. 10. Glemparon orautahi sp. nov., holotype, $\widehat{\partial}$ (NZAC, no. CEC1428). A. Ninth tergite, dorsal. B. Genitalia, ventral. C. Gonostylus, ventral. D. Apex of ejaculatory apodeme and tegmen, ventral. Scale bars $=0.05 \mathrm{~mm}$. Numbered arrows indicate diagnostic characters (see Diagnosis and Other characters). 


\title{
Etymology
}

The specific epithet, orautahi, is the Maori name for Smoky Beach, the place on Stewart Island where the holotype was collected.

\section{Material examined}

\section{Holotype}

NEW ZEALAND: ${ }^{\lambda}$, Stewart Island, Smoky Beach, $46.70^{\circ}$ S, $167.84^{\circ}$ E, 16 Jan. 2000, Malaise trap, R.K. Didham leg. (NZAC, no. CEC1428).

\section{Other characters}

BODY SIZE. $1.7 \mathrm{~mm}$.

HEAD. Eye bridge 1-2 ommatidia long dorsally. Flagellomeres 15; neck of fourth flagellomere 1.5 times the node (Fig. 1G). Palpus slightly longer than head height, 4 setae-bearing segments, apical segment longest of all (Fig. 1C).

Thorax. Pronotal setae present.

WING. Length/width ratio 2.9. Rs short, one fifth of apicR .

LEGs. Basitarsal spines absent.

TeRminalia. Posterior portion of ninth tergite strongly narrowed, covered densely with microtrichia, about 14 megatrichia on posterior edge $\left(\downarrow^{4}\right.$, Fig. 10A). Gonocoxites with separate, narrow, unsetose portion ventrobasally; ventroposterior lobes large, subtriangular; a group of 4-5 dense setae and an inconspicuous double lobe at base of ventral emargination (Fig. 10B). Gonostylus 2.5 times longer than broad, markedly wedge-shaped apically (Fig. 10C). Apex of ejaculatory apodeme membranous, arrowshaped (Fig. 10B).

\section{Distribution and phenology}

The only specimen known of G. orautahi sp. nov. was collected at the height of summer in the native bush of Stewart Island.

\author{
Glemparon otago sp. nov. \\ urn:Isid:zoobank.org:act:A10DF0E4-2C9C-45C9-B85C-79AC1296AE3F
}

Fig. 11

\section{Diagnosis}

The genitalia of this species (Fig. 11) differ from what is typically found in Glemparon. In particular, while the gonostylus is narrowed apically, it is not laterally compressed; the gonocoxites lack membranous areas below the gonostyli; and the apex of the ejaculatory apodeme is not arrow-shaped. An absolutely distinguishing structure is the tegmen, which ends in a pair of sclerotized points ( $\downarrow^{1}$, Fig. 11) and has a pair of lateral processes each consisting of about 10 tubercles $\left(\downarrow^{2}\right.$, Fig. 11).

\section{Etymology}

The specific epithet, otago, is of Maori origin and refers to the Otago Region in the south of New Zealand's South Island, where the holotype was collected. 


\section{Material examined}

\section{Holotype}

NEW ZEALAND: $\widehat{\lambda}$, South Island, Otago, Mount Aspiring National Park, Dart Hut, ca 1000 m a.s.l., 13-14 Feb. 1980, "in bush”, Malaise trap, J.S. Dugdale leg. (NZAC, no. CEC1410).

\section{Other characters}

Body SIZE. $2.3 \mathrm{~mm}$.

HEAD. Eye bridge 3-4 ommatidia long dorsally. Flagellomeres 17; neck of fourth flagellomere 0.6 times the node. Palpus shorter than head height, 4 setae-bearing segments, apical segment longest of all.

Thorax. Pronotal setae absent.

WING. Length/width ratio 2.9. Rs short, one fifth of apicR . $^{\text {. }}$

LEGS. Basitarsal spines present.

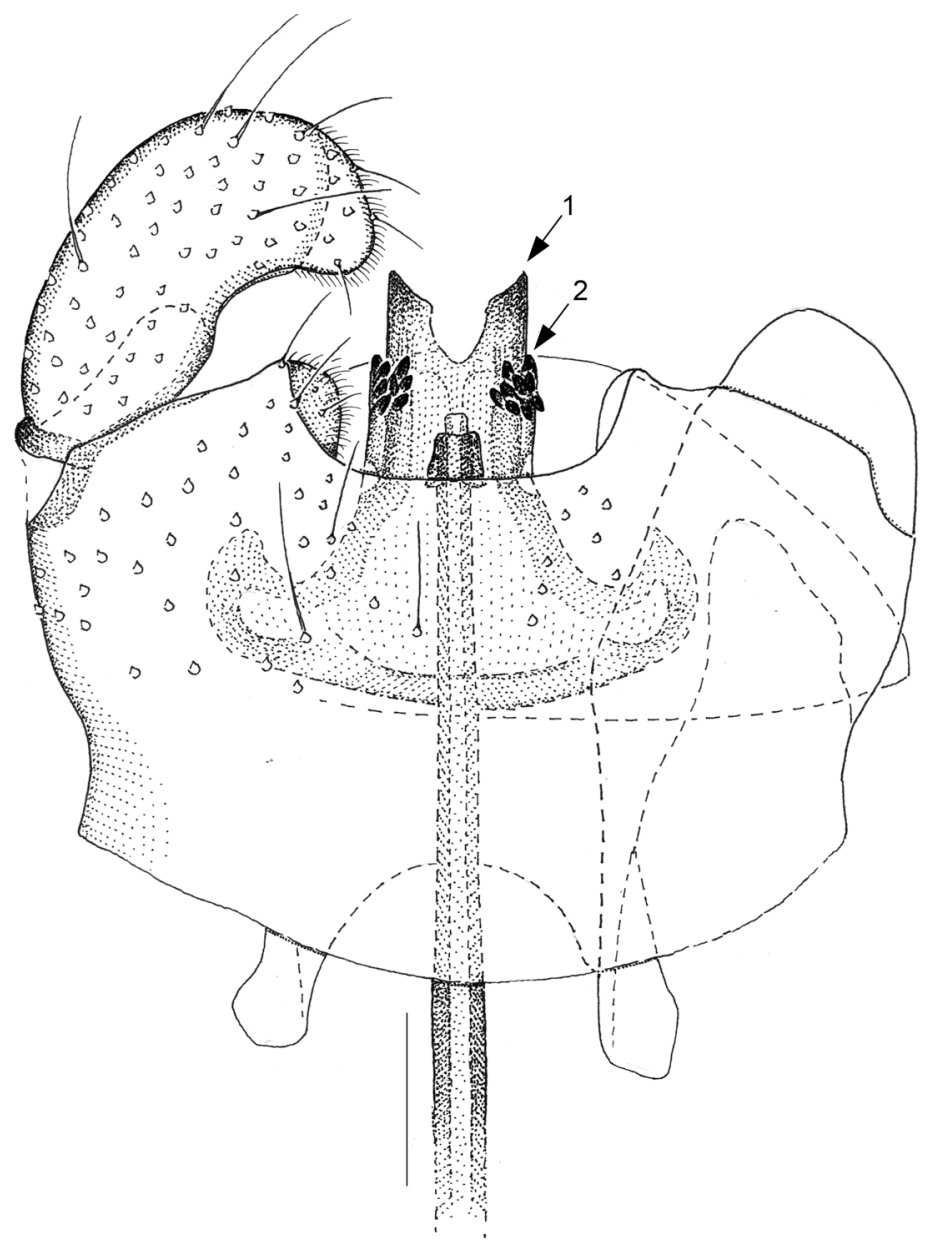

Fig. 11. Genitalia of Glemparon otago sp. nov., holotype, $\widehat{\partial}$ (NZAC, no. CEC1410). Scale bar $=0.05 \mathrm{~mm}$. Numbered arrows indicate diagnostic characters (see Diagnosis). 
Terminalia (Fig. 11). Posterior edge of ninth tergite broadly rounded, with normal microtrichia. Gonocoxites with large unsetose portion ventrobasally; ventroposterior lobes small, rounded; ventral emargination shallow; posteromedial protuberance indistinct, apparently completely membranous (not depicted in Fig. 11); dorsal apodemes shorter and thicker compared with other Glemparon. Gonostylus strongly bent on apical third, with densely microtrichose protuberance dorso-subapically. Ejaculatory apodeme progressively membranous basally, with sclerotized broadening apically.

\section{Discussion}

Our reasons to classify this species in the genus Glemparon are the possession of 17 flagellomeres, i.e., more than the 14 flagellomeres usually found in Dicerurini, and the presence of five out of eight genitalic characters regarded as synapomorphous in Glemparon (see the generic diagnosis above). There is no better, alternative generic placement for $G$. otago sp. nov. The somewhat aberrant genitalic morphology of this species gives an idea of the diversity of structure met in Glemparon, a fact to bear in mind as other unusual, hard-to-place Dicerurini will be found in the future. Glemparon rotoiti sp. nov., which is described below, possibly lies between $G$. otago sp. nov. and other, more typical species of Glemparon.

\section{Distribution and phenology}

The holotype of G. otago sp. nov. was collected in summer in the high mountains of New Zealand's Southern Alps, in a patch of native bush according to the specimen label.

\section{Glemparon pureora sp. nov. urn:1sid:zoobank.org:act:0D7479C0-70CB-4C3F-BF70-DF9D924895CC}

Fig. 12A-B

\section{Diagnosis}

Glemparon pureora sp. nov. is distinguished from congeneric species by the compact gonostylus, which is strongly tapered towards the apex $\left(\downarrow^{1}\right.$, Fig. 12A); the broadly V-shaped gonocoxal emargination (Fig. 12A); the posteromedial protuberance, which has a three-branched sclerotization, with the medial branch forming a ventrally directed process $\left(\downarrow^{2}\right.$, Fig. 12A); and the tegmen, which ends in a pair of serrate processes that point ventrolaterally, and whose posterolateral processes are three-pointed $\left(\downarrow^{3}\right.$, Fig. 12B).

\section{Etymology}

The specific epithet, pureora, refers to the type locality of this species, Pureora Forest Park in the North Island of New Zealand, which protects one of the earth's finest podocarp forests.

\section{Material examined}

\section{Holotype}

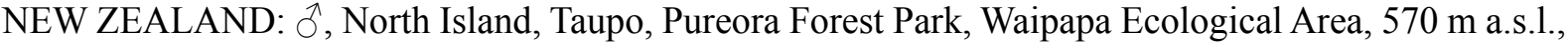
"in shrubland", 2 Feb. 1984, Malaise trap, J. Hutcheson leg. (NZAC, no. CEC1424).

\section{Other characters}

BODY SIZE. $2.0 \mathrm{~mm}$.

HEAD. Eye bridge 2-3 ommatidia long dorsally. Eleven flagellomeres retained; neck of fourth flagellomere 0.9 times the node. Two palpus segments retained. 
ThORax. Pronotal setae present.

WING. Length/width ratio 3.1. Rs short, one fourth of apicR .

LEGS. Basitarsal spines absent.

TERMinalia. Posterior edge of ninth tergite truncate, covered with partially coarse microtrichia (Fig. 12A). Gonocoxites with unsetose portion ventrobasally; ventroposterior lobes inconspicuous (Fig. 12A). Gonostylus twice longer than broad (Fig. 12A). Ejaculatory apodeme thin, with small, sclerotized broadening apically (Fig. 12B).

\section{Distribution and phenology}

The only specimen known of G. pureora sp. nov. was collected in summer, in shrubland embedded in an extensive podocarp forest in New Zealand's North Island. Another species of Glemparon, $G$. waipapa sp. nov., was captured one month later at the same site, perhaps even with the same Malaise trap.

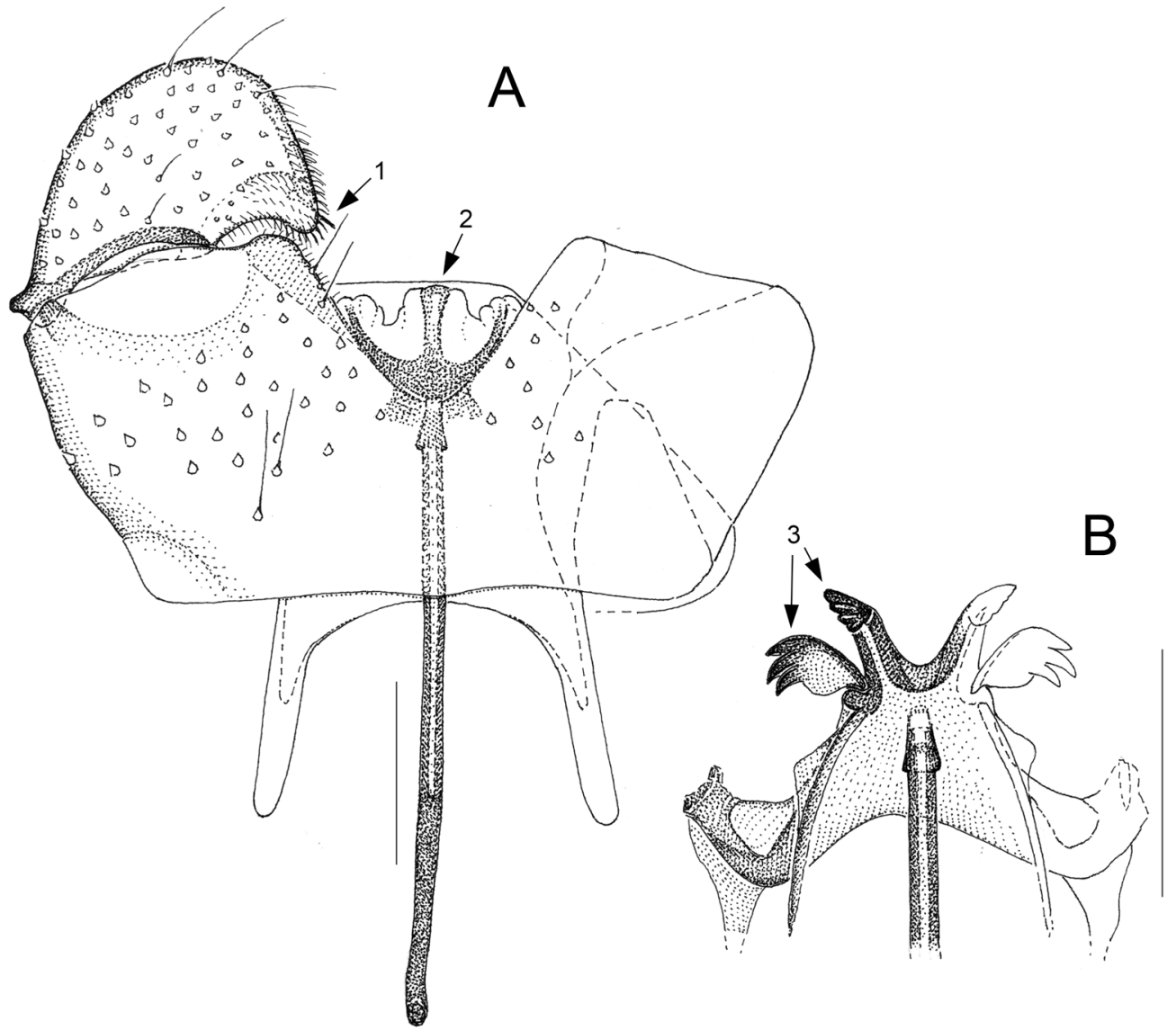

Fig. 12. Glemparon pureora sp. nov., holotype, ô (NZAC, no. CEC1424). A. Genitalia, ventral. B. Apex of ejaculatory apodeme and tegmen, ventral. Scale bars $=0.05 \mathrm{~mm}$. Numbered arrows indicate diagnostic characters (see Diagnosis). 
Glemparon rakiura sp. nov.

urn:lsid:zoobank.org:act:16A4696C-1AB8-43FE-A675-C1159DCCDBDF

Fig. $13 \mathrm{~A}-\mathrm{C}$

\section{Diagnosis}

Glemparon rakiura sp. nov. is distinguished by the gonocoxal ventroposterior lobes, which are conspicuous by their globular shape and dense cover with thick, spine-like microtrichia dorsomedially ( $\downarrow^{1}$, Fig. 13A). The gonostylus, which basically is rather slender, has a densely microtrichose protuberance dorsobasally $\left(\downarrow^{2}\right.$, Fig. 13A). The ninth tergite has a narrow posterior portion, which is separated from the much broader anterior portion by a constriction and is covered with microtrichia of various sizes; the posterior edge is provided with about 10 megatrichia $\left(\downarrow^{3}\right.$, Fig. 13B).

\section{Etymology}

The specific epithet, rakiura, is the Maori name for Stewart Island, the provenance of the holotype specimen.

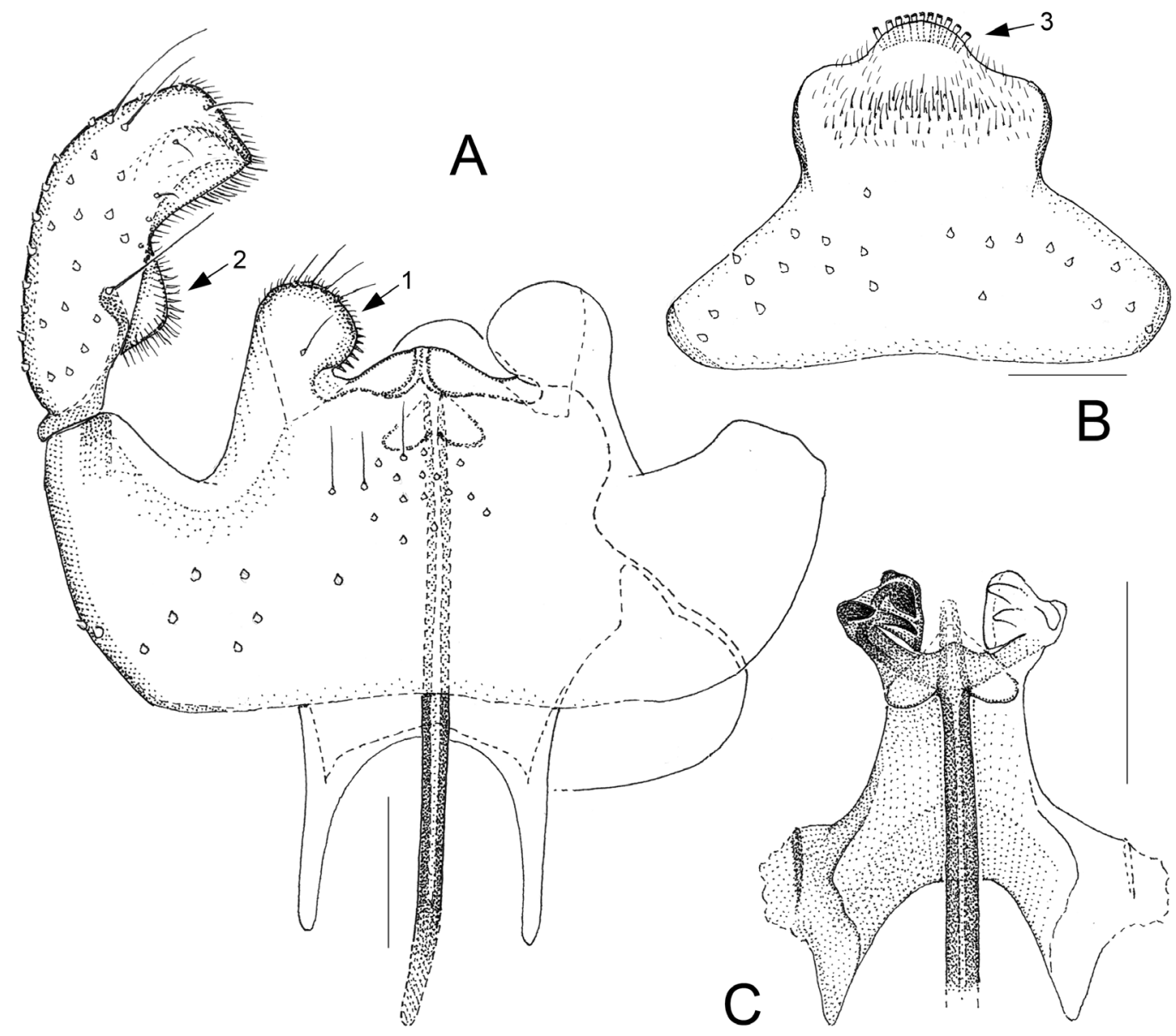

Fig. 13. Glemparon rakiura sp. nov., holotype, ${ }_{0}^{\lambda}$ (NZAC, no. CEC1420). A. Genitalia, ventral. B. Ninth tergite, dorsal. C. Apex of ejaculatory apodeme and tegmen, ventral. Scale bars $=0.05 \mathrm{~mm}$. Numbered arrows indicate diagnostic characters (see Diagnosis). 


\title{
Material examined
}

Holotype

NEW ZEALAND: ${ }^{\Uparrow}$, Stewart Island, Christmas Village Hut, $46.74^{\circ} \mathrm{S}, 167.97^{\circ} \mathrm{E}, 18$ Jan. 2000, Malaise trap, R.K. Didham leg. (NZAC, no. CEC1420).

\section{Other characters}

BODY SIZE. $1.8 \mathrm{~mm}$.

HEAD. Eye bridge $0-1$ ommatidium long dorsally. Flagellomeres 14; neck of fourth flagellomere 1.6 times the node. Palpus slightly longer than head height, 4 setae-bearing segments, apical segment conspicuously long, almost twice as long as preceding segment.

Thorax. Pronotal setae present.

WING. Length/width ratio 3.0. Rs short, one sixth of apicR .

Legs. Basitarsal spines absent.

Terminalia. Posteromedial protuberance of gonocoxites small, with fold resembling an inverted Y-shape in center (Fig. 13A). Gonostylus bent beyond midlength, 3.0 times as long as broad (Fig. 13A). Apex of ejaculatory apodeme small, membranous, arrow-shaped; base unsclerotized (Fig. 13C). Posterolateral processes of tegmen each with 3 or so small, finger-shaped tubercles (Fig. 13C).

\section{Distribution and phenology}

See G. didhami sp. nov.

\author{
Glemparon rotoiti sp. nov. \\ urn:1sid:zoobank.org:act:030EDECD-B4EF-4500-A2B7-73615D7EEB1B \\ Fig. 14A-C
}

\section{Diagnosis}

The elongate gonostylus of simple shape is not compressed at the apex, which is rounded and covered with dense microtrichia $\left(\downarrow^{1}\right.$, Fig. 14A). The gonocoxites are peculiar for both the membranous portions ventroposteriorly, whose outline resembles a stair $\left(\downarrow^{2}\right.$, Fig. 14A), and the ventral emargination, which is large, somewhat rectangular and vaguely delineated at the base ( $\downarrow^{3}$, Fig. 14A). The ninth tergite has an almost truncate, strongly sclerotized posterior edge ( $\downarrow^{4}$, Fig. 14B), which is a unique feature in Glemparon, and on the inside numerous small tubercles in indistinct rows. The tegmen is provided with a pair of sclerotized, serrate points ( $\downarrow^{5}$, Fig. 14C) and, at the points' bases, sclerotized processes each consisting of two curved teeth $\left(\downarrow^{6}\right.$, Fig. 14C).

\section{Etymology}

The specific epithet refers to Lake Rotoiti in the north of New Zealand's South Island, where the holotype was collected.

\section{Material examined}

\section{Holotype}

NEW ZEALAND: $\widehat{\jmath}$, South Island, Tasman, Nelson Lakes National Park, Lake Rotoiti, $640 \mathrm{~m}$ a.s.1., 20 Dec. 2000, southern beech forest, Malaise trap, Department of Conservation St. Arnaud leg. (NZAC, no. CEC1425). 


\section{Other characters}

BODY SIZE. $1.6 \mathrm{~mm}$.

HEAD. Eye bridge 1-2 ommatidia long dorsally. Flagellomeres 12; apical flagellomere merged of two bodies; neck of fourth flagellomere 0.7 times the node. Palpus clearly shorter than head height, 4 setaebearing segments, apical segment longest of all.

THorax. Pronotal setae absent.

WING. Length/width ratio 2.6. Rs short, one fifth of apicR .

LEGS. Basitarsal spines present.

TERminalia. Ventroposterior lobes of gonocoxites indistinct; posteromedial protuberance simple, no obvious structuring (Fig. 14A). Gonostylus almost 3.0 times as long as broad (Fig. 14A). Apex of ejaculatory apodeme small, membranous, arrow-shaped (Fig. 14A, C).

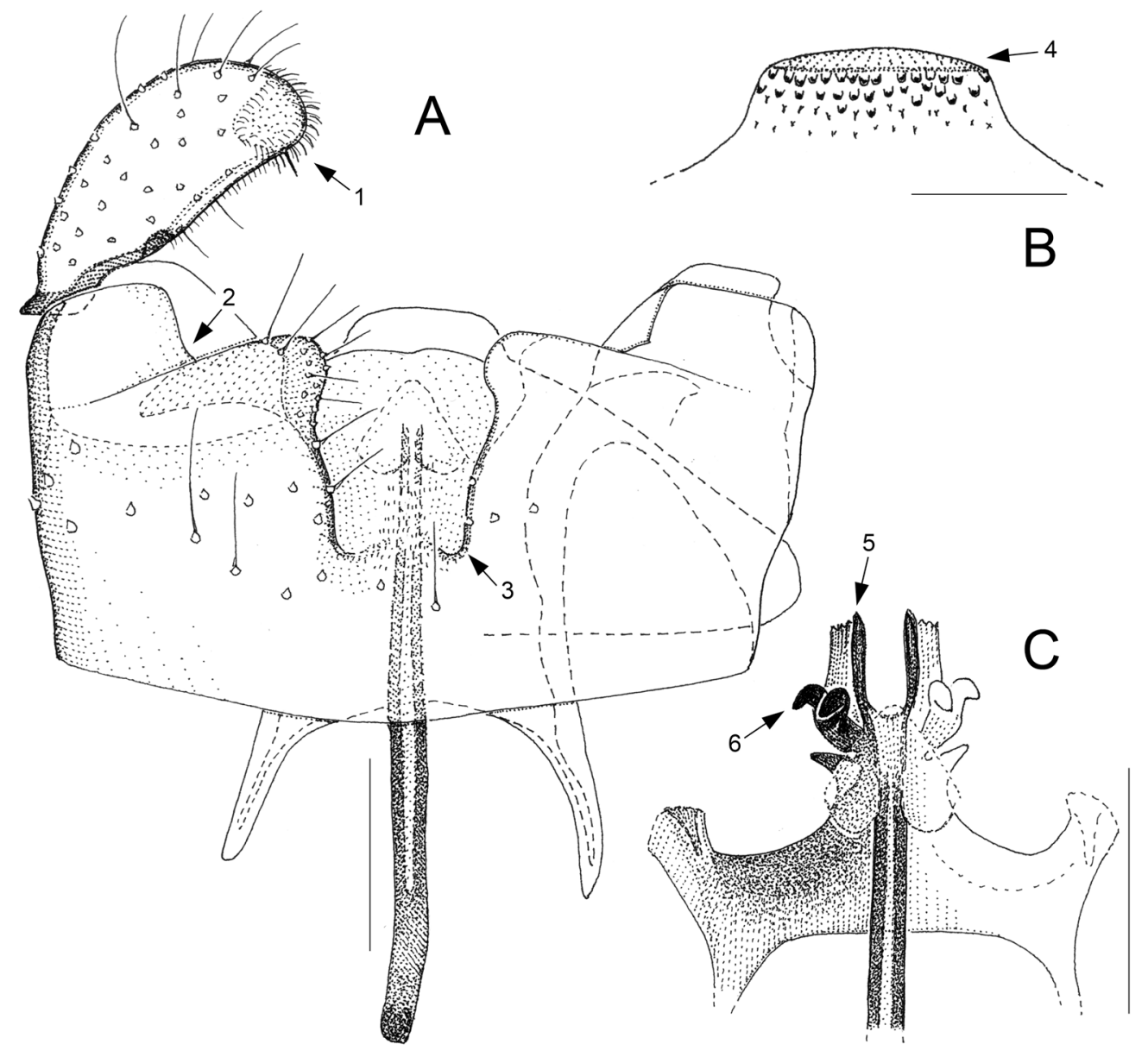

Fig. 14. Glemparon rotoiti sp. nov., holotype, §̊ (NZAC, no. CEC1425). A. Genitalia, ventral. B. Apex of ninth tergite, ventral. C. Apex of ejaculatory apodeme and tegmen, ventral. Scale bars: A, C $=0.05 \mathrm{~mm}$; $\mathrm{B}=0.025 \mathrm{~mm}$. Numbered arrows indicate diagnostic characters (see Diagnosis). 


\section{Distribution and phenology}

The holotype of G. rotoiti sp. nov. was collected in summer, in an extensive native forest in the north of New Zealand's South Island.

Glemparon rotoroa sp. nov.

urn:1sid:zoobank.org:act:9C99F477-E0D5-4817-956A-E8E294F2E587

Fig. $15 \mathrm{~A}-\mathrm{C}$

\section{Diagnosis}

Glemparon rotoroa sp. nov. is an absolutely distinctive species, with the following genitalic characters. The gonocoxites have a pair of conspicuously large lobes ventroposteriorly, from which the strongly

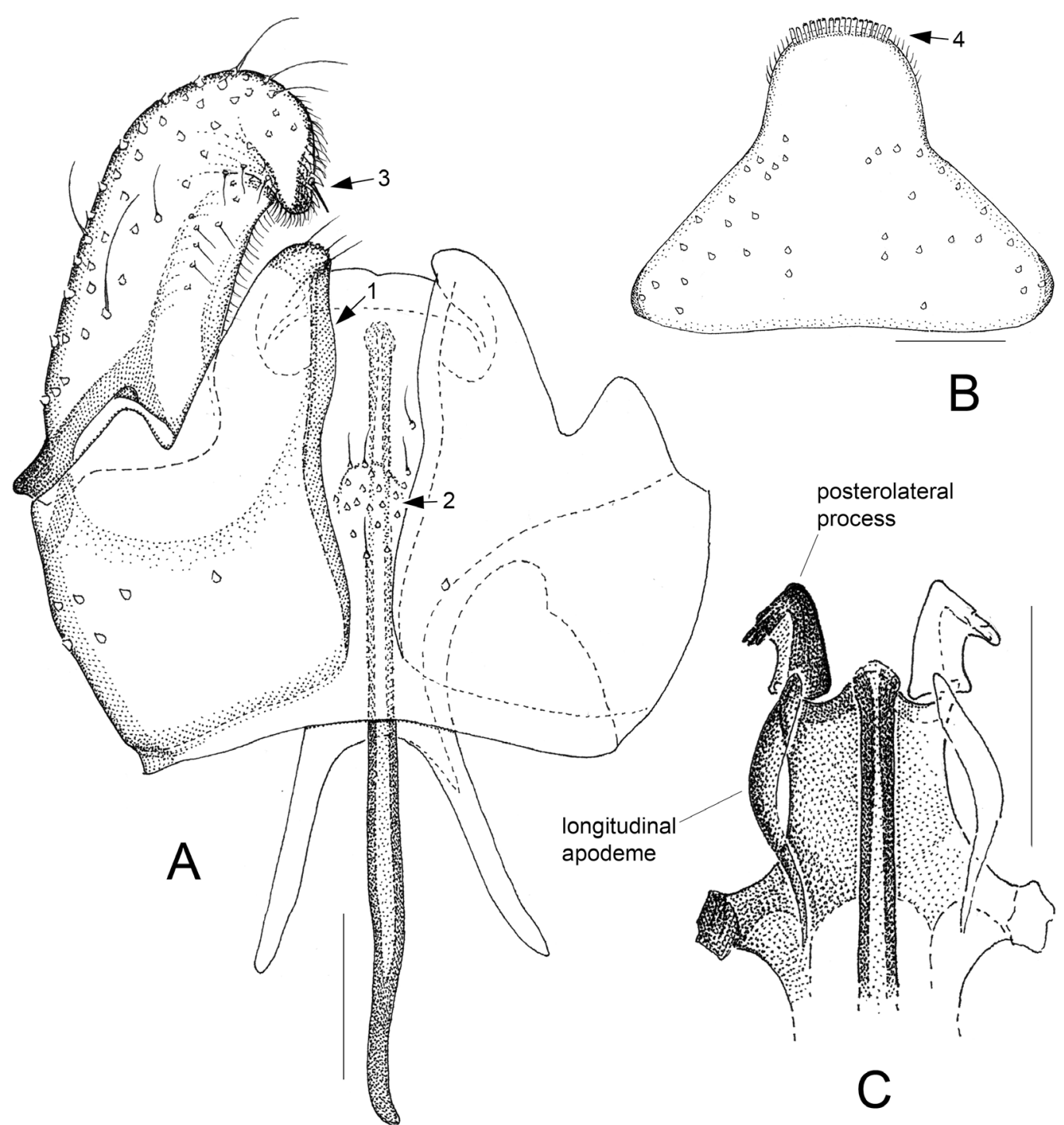

Fig. 15. Glemparon rotoroa sp. nov., $\widehat{\partial}$. A, C. Holotype (NZAC, no. CEC1415). A. Genitalia, ventral. B. Ninth tergite, dorsal, paratype (NZAC, no. CEC1416). C. Apex of ejaculatory apodeme and tegmen, ventral. Scale bars $=0.05 \mathrm{~mm}$. Numbered arrows indicate diagnostic characters (see Diagnosis). 
sclerotized margins of the ventral emargination set out $\left(\downarrow^{1}\right.$, Fig. 15A). Close to the base of the emargination, on a slight ridge, is a dense group of about 20 setulae $\left(\downarrow^{2}\right.$, Fig. 15A); other ventral setae are very sparse. The elongate gonostylus with hook-shaped apex is directed posteriorly rather than medially ( $\downarrow^{3}$, Fig. 15A). The posterior portion of the ninth tergite, which is much narrower than the anterior portion, has about 15 marginal megatrichia $\left(\downarrow^{4}\right.$, Fig. 15B).

\section{Etymology}

The specific epithet refers to Lake Rotoroa in the north of New Zealand's South Island, where the holotype was collected.

\section{Material examined}

\section{Holotype}

NEW ZEALAND: ${ }^{\lambda}$, South Island, Tasman, Nelson Lakes National Park, Lake Rotoroa, 450 m a.s.l., 15 Jan. 2001, mixed podocarp/southern beech forest, Malaise trap, Department of Conservation St. Arnaud leg. (NZAC, no. CEC1415).

\section{Paratypes}

NEW ZEALAND: $2 \precsim ð$, same data as for holotype (NZAC, nos CEC1416-CEC1417).

\section{Other characters}

BoDy SIZE. $1.7 \mathrm{~mm}$.

HEAD. Eye bridge 1-2 ommatidia long dorsally. Flagellomeres 12; fourth flagellomere with neck and node equally long. Palpus as long as head height, 4 setae-bearing segments; apical segment longest of all.

THORAX. Pronotal setae present.

WING. Length/width ratio 2.9. Rs short, one eighth of apicR 1 .

LEGs. Basitarsal spines absent.

Terminalia. Gonocoxites: membranous areas below gonostyli large; dorsal apodemes closely adjacent to each other; posteromedial protuberance without obvious structuring (Fig. 15A). Gonostylus more than 3.0 times longer than broad; outside densely setose; inside with dense, fine pubescence, a very few fine setulae (Fig. 15A). Apex of ejaculatory apodeme unmodified (Fig. 15C). Apices of tegminal processes bent ventrolaterally, with several inconspicuous spikes; longitudinal apodemes unusually distinct (Fig. 15C).

\section{Distribution and phenology}

See G. aotearoa sp. nov.

Glemparon tewaipounamu sp. nov. urn:1sid:zoobank.org:act:77EE535D-663A-4A5C-84FE-72E88BAD02FB

Fig. 16A-C

\section{Diagnosis}

A combination of genitalic characters is characteristic of G. tewaipounamu sp. nov., as follows. The elongate, slightly bent gonostylus has a densely microtrichose bulge dorsobasally ( $\downarrow^{1}$, Fig. 16B). Of 
the gonocoxites, the posteromedial protuberance is largely unmodified except for inconspicuous folds, which indicate some kind of structuring $\left(\downarrow^{2}\right.$, Fig. 16A); and the medial bridges have a section with large, dense microtrichia ( $\downarrow^{3}$, Fig. 16A). The posterolateral processes of the tegmen, which are strongly sclerotized, are a complicated assemblage of teeth, tubercles and serrate ridges ( $\downarrow^{4}$, Fig. 16C).

\section{Etymology}

The name of this species, tewaipounamu, is the original Maori name for the South Island of New Zealand, where the holotype was collected.

\section{Material examined}

\section{Holotype}

NEW ZEALAND: $\widehat{\jmath}$, South Island, Tasman, Nelson Lakes National Park, Lake Rotoroa, $450 \mathrm{~m}$ a.s.l., 15 Jan. 2001, mixed podocarp/southern beech forest, Malaise trap, Department of Conservation St. Arnaud leg. (NZAC, no. CEC1418).

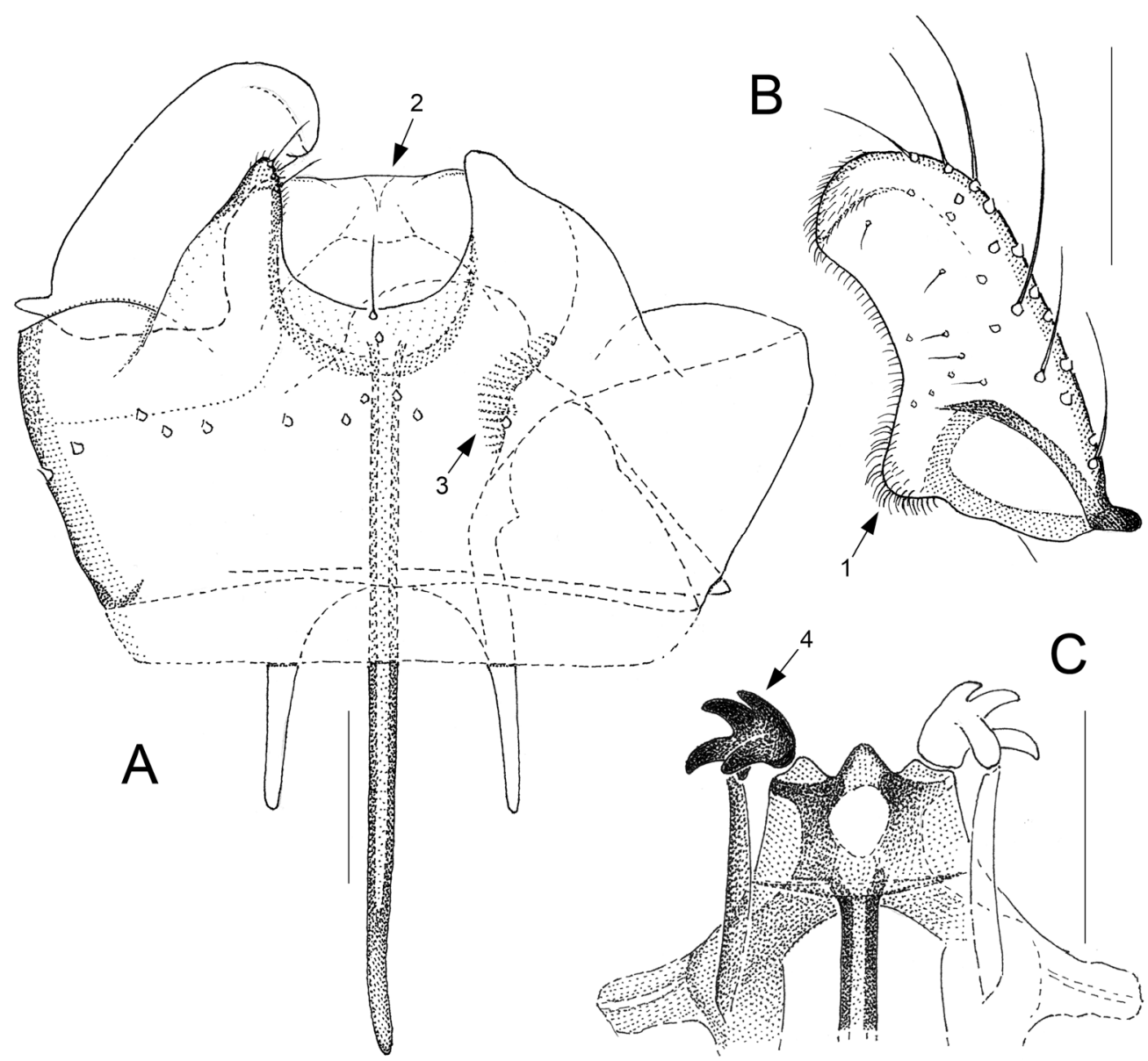

Fig. 16. Glemparon tewaipounamu sp. nov., holotype, đ̊ (NZAC, no. CEC1418). A. Genitalia, ventral. B. Gonostylus, ventromedial. C. Apex of ejaculatory apodeme and tegmen, ventral. Scale bars $=0.05 \mathrm{~mm}$. Numbered arrows indicate diagnostic characters (see Diagnosis). 


\section{Other characters}

BODY SIZE. $1.7 \mathrm{~mm}$.

HEAD. Eye bridge 1-2 ommatidia long dorsally. Flagellomeres 13; apical flagellomere merged of two bodies; neck of fourth flagellomere 1.3 times the node. Palpus slightly shorter than head height, 4 setaebearing segments; apical segment longest of all.

THORAx. Pronotal setae present.

WING. Length/width ratio 3.2. Rs short, one seventh of apicR . $_{\text {. }}$

LEGs. Basitarsal spines absent.

Terminalia. Posterior edge of ninth tergite slightly three-lobed, central lobe rounded, with about 15 megatrichia, flanked by angular-shaped, densely microtrichose side lobes. Gonocoxites sparsely setose ventrally; membranous areas below gonostyli large; ventral emargination U-shaped; ventroposterior lobes large, subtriangular (Fig. 16A). Gonostylus twice longer than broad; outside densely setose; inside with dense, fine pubescence, a very few fine setulae (Fig. 16B). Apex of ejaculatory apodeme largely unmodified (Fig. 16C). Tegmen with distinct pattern of sclerotization in center (Fig. 16C).

\section{Distribution and phenology}

See G. aotearoa sp. nov.

$$
\begin{aligned}
& \text { Glemparon waipapa sp. nov. } \\
& \text { urn:1sid:zoobank.org:act:629C06FF-EB6C-4D3E-AB2B-D7C995AA4A48 }
\end{aligned}
$$

Fig. $17 \mathrm{~A}-\mathrm{B}$

\section{Diagnosis}

This is another absolutely distinctive species. No Glemparon other than G. waipapa sp. nov. has an ejaculatory apodeme with such a sclerotized, lance-shaped apex ( $\downarrow^{1}$, Fig. 17B) and tegminal processes shaped like wine grapes $\left(\downarrow^{2}\right.$, Fig. 17B). Another diagnostic feature is the large, sclerotized process arising from the gonocoxal posteromedial protuberance ( $\downarrow^{3}$, Fig. 17A).

\section{Etymology}

The specific epithet, waipapa, highlights the Waipapa Ecological Area of the Pureora Forest Park in New Zealand's North Island, where the holotype of this species was collected.

\section{Material examined}

\section{Holotype}

NEW ZEALAND: $\widehat{\jmath}$, North Island, Taupo, Pureora Forest Park, Waipapa Ecological Area, 570 m a.s.l., 1 Mar. 1984, "in shrubland”, Malaise trap, J. Hutcheson leg. (NZAC, no. CEC1423).

\section{Other characters}

BODY SIZE. $1.6 \mathrm{~mm}$.

HEAD. Eye bridge 1-2 ommatidia long dorsally. Nine flagellomeres retained; fourth flagellomere with neck and node equally long. Palpus clearly shorter than head height, first segment very small, unsetose, second to forth segments with ordinary setae; apical segment longest of all. 
THORAX. Pronotal setae present.

WING. Length/width ratio 3.2. Rs short, one fifth of apicR .

LEGS. Basitarsal spines present.

Terminalia. Posterior edge of ninth tergite broadly rounded, about 15 megatrichia medially flanked by dense, large, hair-like microtrichia. Gonocoxites with separate, narrow, unsetose portion ventrobasally; ventral setae reduced to a transversal stripe in center; membranous areas below gonostyli large; ventral emargination small, somewhat rectangular; ventroposterior lobes massive, rounded (Fig. 17A). Gonostylus simple, more than twice as long as broad, slightly bent (Fig. 17A). Tegmen, apart from its posterolateral processes, of simple structure (Fig. 17B).

\section{Distribution and phenology}

See G. pureora sp. nov.

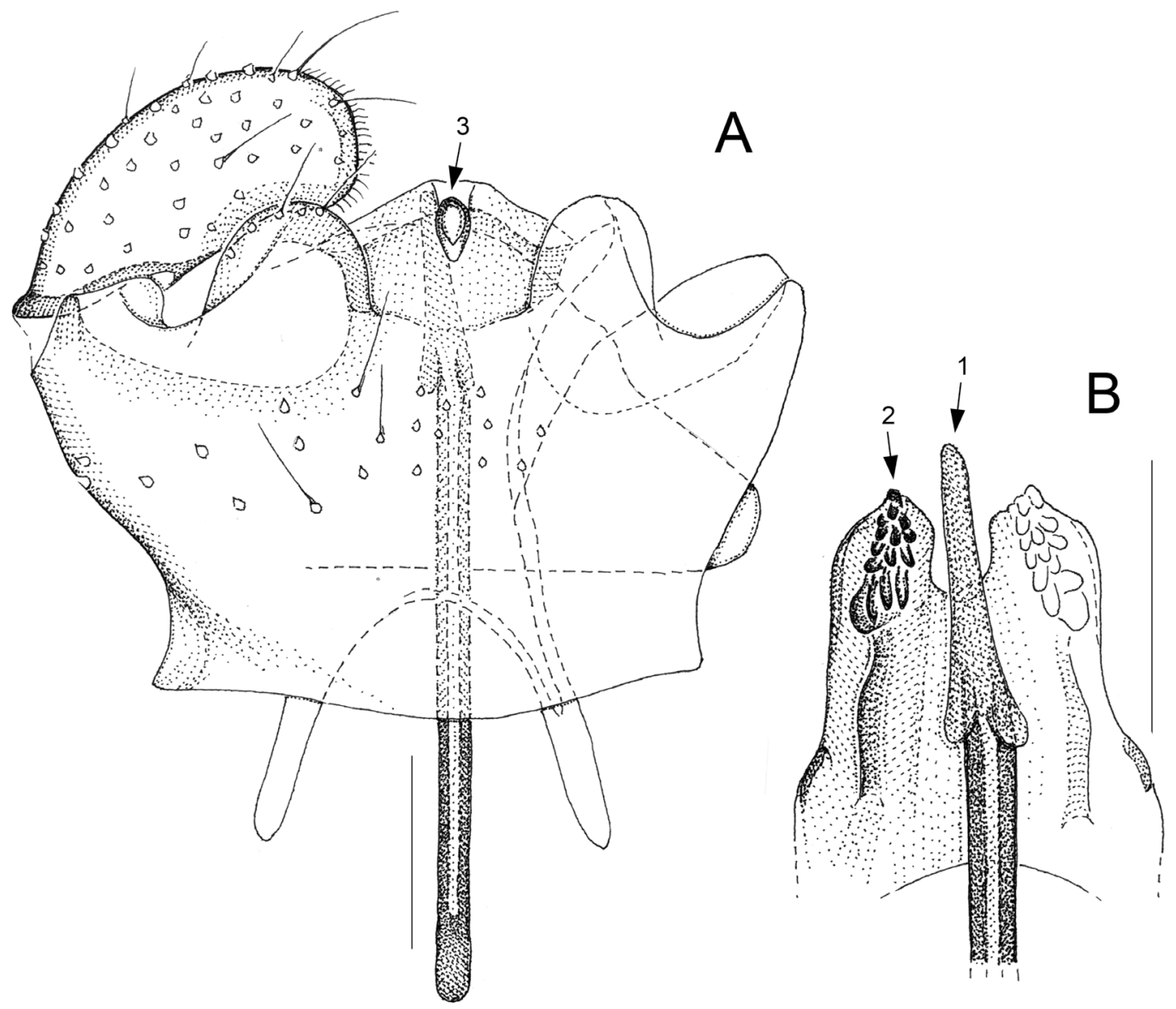

Fig. 17. Glemparon waipapa sp. nov., holotype, $\widehat{\partial}$ (NZAC, no. CEC1423). A. Genitalia, ventral. B. Apex of ejaculatory apodeme and tegmen, ventral. Scale bars $=0.05 \mathrm{~mm}$. Numbered arrows indicate diagnostic characters (see Diagnosis). 
Glemparon waipoua sp. nov.

urn:1sid:zoobank.org:act:8C07CF84-F7E3-4506-B538-C69C1F43B4E5

Fig. 18A-C, E

\section{Diagnosis}

A combination of genitalic characters is diagnostic of $G$. waipoua sp. nov., as follows. The elongate gonostylus is peculiar for its pointed apex $\left(\downarrow^{1}\right.$, Fig. 18A); the ventral emargination of the gonocoxites, which is small, has a microtrichose bulge and no setae basally ( $\downarrow^{2}$, Fig. 18C); and the tegmen has two transverse struts $\left(\downarrow^{3}\right.$, Fig. 18E) as well as posterolateral processes each with $8-9$ sclerotized teeth $\left(\downarrow^{4}\right.$, Fig. 18E).

\section{Etymology}

The specific epithet, waipoua, refers to Waipoua Forest, a sanctuary for the finest kauri forest preserved in New Zealand, which is the type locality of this new species.

\section{Material examined}

\section{Holotype}

NEW ZEALAND: $\widehat{\jmath}$, North Island, Northland, Waipoua Forest, near road SH12, $300 \mathrm{~m}$ a.s.1., 24 Jul.17 Aug. 2001, old-growth mixed kauri/podocarp forest, Malaise trap, M. and C. Jaschhof legs (NZAC, no. CEC1412).

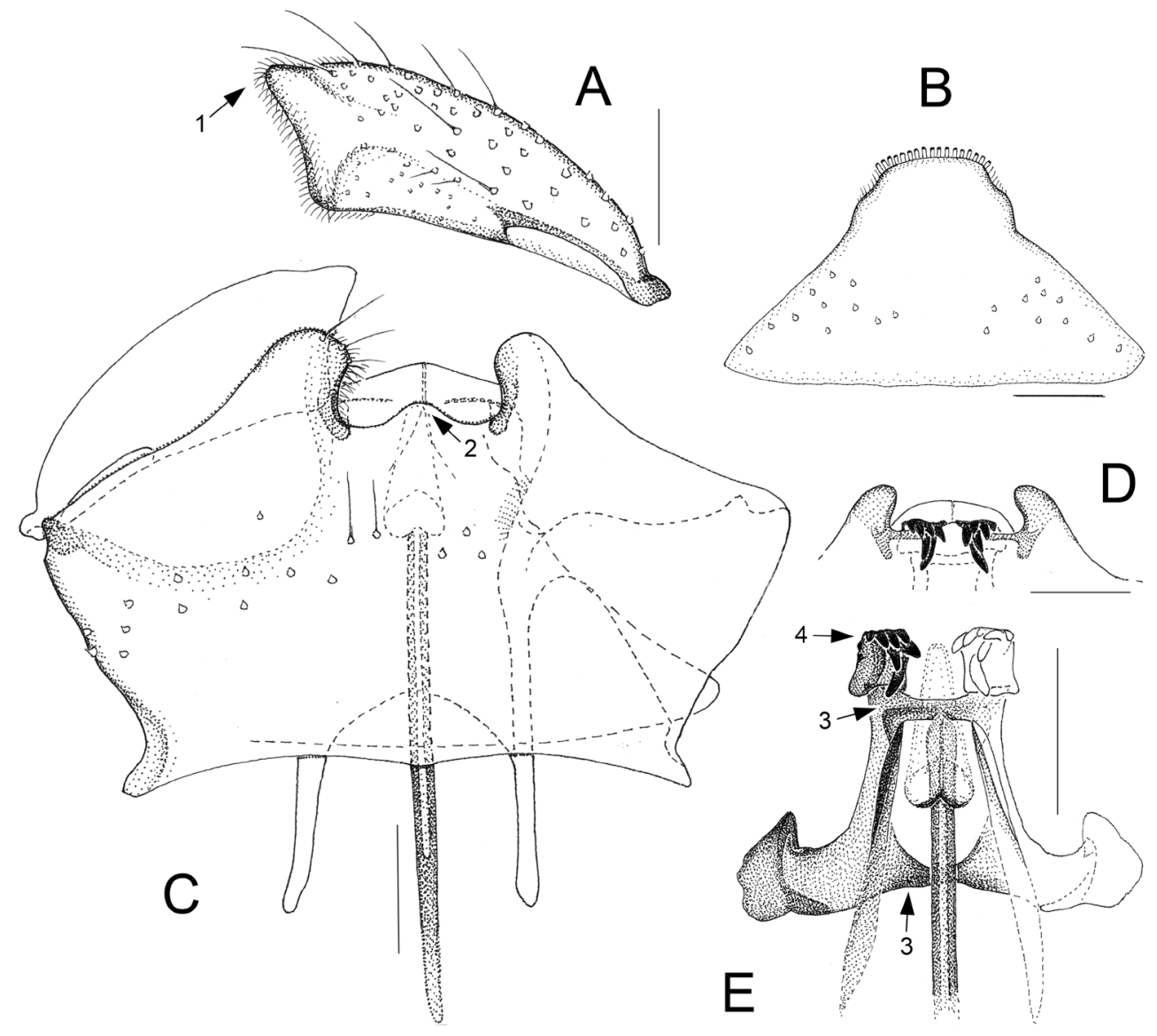

Fig. 18. Glemparon waipoua sp. nov., holotype, ổ (NZAC, no. CEC1412) (A-C, E) and possibly closely related species (D). A. Gonostylus, lateral. B. Ninth tergite, dorsal. C. Genitalia, ventral. D. Ventroposterior edge of gonocoxites and tegminal processes, ventral. E. Apex of ejaculatory apodeme and tegmen, ventral. Scale bars $=0.05 \mathrm{~mm}$. Numbered arrows indicate diagnostic characters (see Diagnosis). 


\title{
Other characters
}

BODY SIZE. $2.1 \mathrm{~mm}$.

HEAD. Eye bridge 1-2 ommatidia long dorsally. Eight flagellomeres retained; neck of fourth flagellomere 1.9 times the node. Palpus almost as long as head height, 4 setae-bearing segments; apical segment conspicuously long, nearly twice as long as preceding segment.

THORAX. Pronotal setae present.

WING. Length/width ratio 3.0. Rs short, one fifth of apicR .

Legs. Basitarsal spines present.

TERMINALIA. Posterior edge of ninth tergite with about 20 megatrichia medially flanked by inconspicuous microtrichose lobes (Fig. 18B). Gonocoxites with narrow, unsetose portion ventrobasally; ventral setae reduced to a transversal stripe in center; membranous areas below gonostyli large; ventroposterior lobes small, rounded; posteromedial protuberance unmodified except for a distinct longitudinal fold; medial bridges with short, densely microtrichose sections (Fig. 18C). Gonostylus more than 3.0 times longer than broad (Fig. 18A). Ejaculatory apodeme with elongate, membranous apex (Fig. 18E).

\section{Distribution and phenology}

This species, known only from the holotype, was collected in the subtropical winter of New Zealand's Northland, in a forest predominated by kauri trees.

\section{Notes on a possibly closely related, unnamed species}

Among the Glemparon studied here is a male (NZAC, no. CEC1413) from the Westland Region in New Zealand's South Island, which largely fits the description of $G$. waipoua sp. nov. given above, with the exception of the genitalic structures that resemble those shown in Figure 18D. In this specimen, the gonocoxal ventroposterior lobes are smaller; the ventral emargination has a sclerotized basal edge (no microtrichose bulge as found in G. waipoua sp. nov.); and, most importantly, the tooth-bearing processes of the tegmen protrude beyond the gonocoxal wall, which is something we have noted in no other Glemparon. We refrain from describing this specimen as a new species, because it resembles G. waipoua sp. nov. in all other respects and we cannot be absolutely sure whether the peculiarities observed are just due to preparation artifacts.

\section{Species of Glemparon in Tasmania}

\author{
Glemparon manuka sp. nov. \\ urn:1sid:zoobank.org:act:49E0AEC8-D15A-4E75-ABBE-F39B9B532D13 \\ Figs 1A, F, 19A-B
}

\section{Diagnosis}

The complex genitalic structures found in G. manuka sp. nov. make this the most unusual species we have seen of Glemparon. The tegmen and ejaculatory apodeme form a structural unit, which is also linked to the gonocoxal ventral wall; for simplicity we refer to this entire structure as the tegmen. The abundance of serrate and tooth-bearing lobes on the tegmen, which is unique, is shown in Figure 19A. The gonocoxal posteromedial protuberance is missing as a distinct structure, but we suppose it is merged into the tegmen. 


\section{Etymology}

The specific epithet, manuka, refers to the Manuka Road in the Warra Long Term Ecological Research site, Tasmania, where the holotype specimen of this species was collected. Manuka (Leptospermum scoparium J.R. Forst. \& G. Forst.), a small tree of the Myrtaceae family, is a common native of southeast Australia and New Zealand.

\section{Material examined}

\section{Holotype}

AUSTRALIA: $\widehat{\jmath}$, Tasmania, Warra Long Term Ecological Research site, Manuka Road, 19 May 2004, eucalypt forest, Malaise trap, R. Bashford leg. (AM, no. CEC1409).

\section{Differential diagnosis}

Genitalic morphology indicates that G. manuka sp. nov. is most closely related to G. rotoroa sp. nov. from New Zealand (Fig. 15). The gonostyli, gonocoxites and ninth tergites of both species are broadly similar, while the tegmina are completely different.

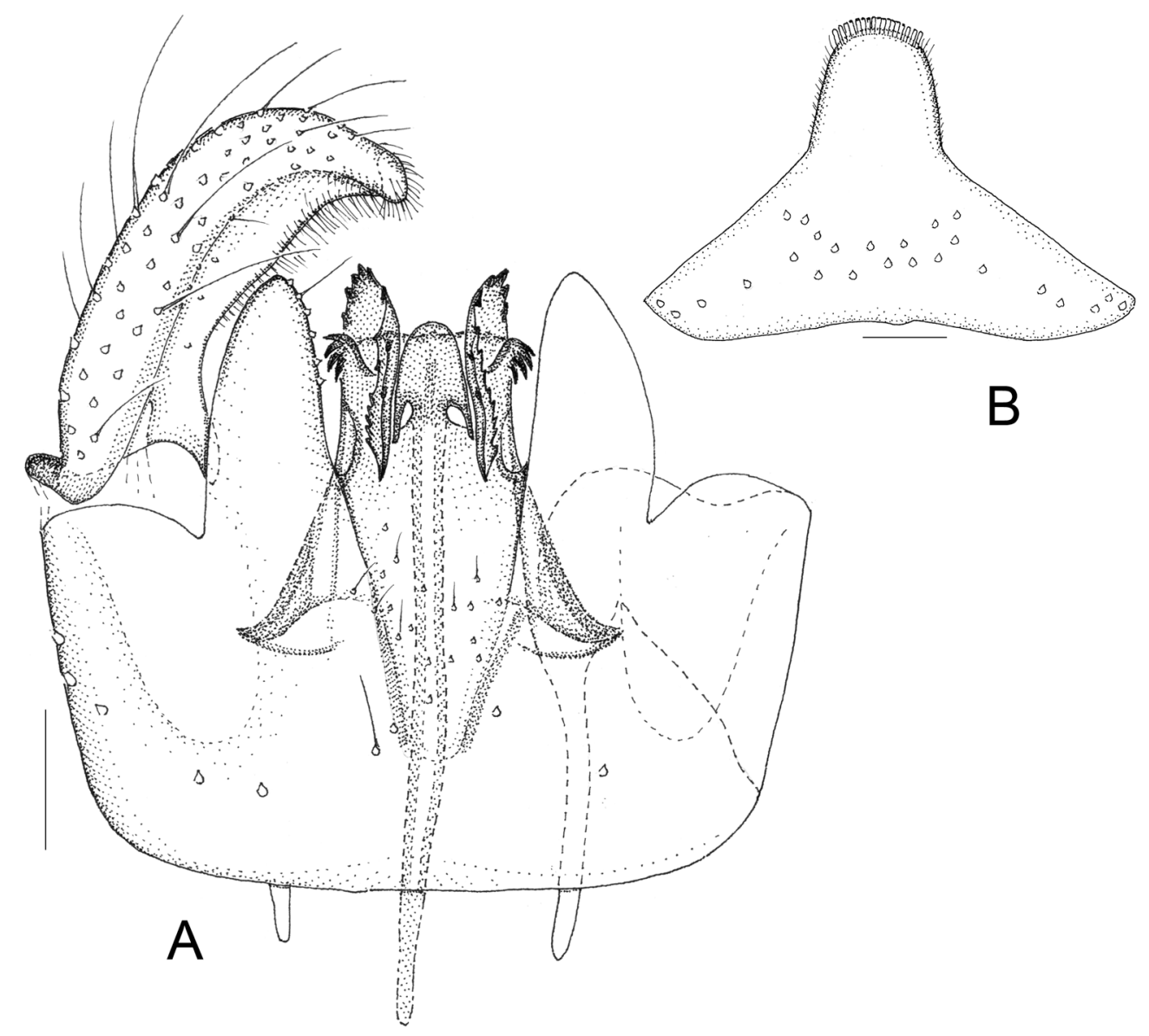

Fig. 19. Glemparon manuka sp. nov., holotype, $\widehat{\curlywedge}$ (AM, no. CEC1409). A. Genitalia, ventral. B. Ninth tergite, dorsal. Scale bars $=0.05 \mathrm{~mm}$. 


\title{
Other characters
}

BODY SIZE. $2.1 \mathrm{~mm}$.

HEAD. Eye bridge 0-1 ommatidium long dorsally. Nine flagellomeres retained; neck of fourth flagellomere 2.2 times longer than node (Fig. 1F). Palpus about as long as head height, 4 setae-bearing segments; apical segment longest of all.

THORAX. Pronotal setae present.

WING. Length/width ratio 3.2. Rs short, one twelfth of apicR .

LeGs. Basitarsal spines present (Fig. 1A).

TERMINALIA. Ninth tergite markedly narrowed posteriorly, posterior edge with about 20 dense megatrichia (Fig. 19B). Gonocoxites very sparsely setose ventrally; ventral emargination filled with membrane with fine microtrichia and setulae; ventroposterior lobes conspicuously large (Fig. 19A). Gonostylus 3.0 times longer than broad; strongly bent on apical third; outside densely setose; inside and apex with dense microtrichia and a few setulae (Fig. 19A). Ejaculatory apodeme shorter than in other Glemparon, as long as gonocoxites; base weakly sclerotized; apex broadened, strongly sclerotized, merged with tegmen (Fig. 19A).

\section{Distribution and phenology}

This species is known from a single specimen collected in autumn, in a stretch of old-growth wet eucalypt forest in lowland Tasmania.

\author{
Glemparon warra $\mathrm{sp}$. nov. \\ urn:1sid:zoobank.org:act:B6B07566-CCE4-43AB-B348-5FA66F74B712
}

Figs 1B, 20A-D

\section{Diagnosis}

The tegmen consists of a massive, subtrapezoid portion basally and a biramous portion apically, both separated by a constriction; the rami end in leaf-shaped processes whose bases are covered with numerous tiny spikes $\left(\downarrow^{1}\right.$, Fig. 20C). The arrow-shaped apex of the ejaculatory apodeme is sclerotized ( $\downarrow^{2}$, Fig. 20D), not membranous as in most other species of Glemparon. The gonostylus is slightly broadened towards the apex ( $\downarrow^{3}$, Fig. 20B).

\section{Etymology}

The specific epithet, warra, refers to the type locality of this species. The Warra Long Term Ecological Research (LTER) site in southern Tasmania is a prime example of a temperate broadleaf (eucalypt) wet forest.

\section{Material examined}

\section{Holotype}

AUSTRALIA: ${ }^{\lambda}$, Tasmania, Warra Long Term Ecological Research site, Mt. Weld, $43.07^{\circ} \mathrm{S}, 146.67^{\circ} \mathrm{E}$, 100 m a.s.l., 27 Feb. 2001, eucalypt forest, Malaise trap, N. Doran \& R. Bashford leg. (AM, no. CEC1408).

\section{Other characters}

BoDY SIZE. $1.9 \mathrm{~mm}$. 
HEAD. Eye bridge 0-1 ommatidium long dorsally. Fourteen flagellomeres retained; neck of fourth flagellomere 1.4 times longer than node. Palpus shorter than head height, 4 setae-bearing segments; apical segment longest of all.

Thorax. Pronotal setae absent.

WING. Length/width ratio 3.3. Rs short, one eighth of apicR .

Legs. Basitarsal spines absent.

Terminalia. Posterior edge of ninth tergite broadly rounded to truncate (indicated in Fig. 20A), with dense, large microtrichia. Gonocoxites (Fig. 20A): ventral emargination shaped like widely open U, flanked by small, subtriangular lobes; posteromedial protuberance partly slightly sclerotized; a separate, narrow, unsetose section ventrobasally. Gonostylus 2.5 times longer than broad; densely setose except the

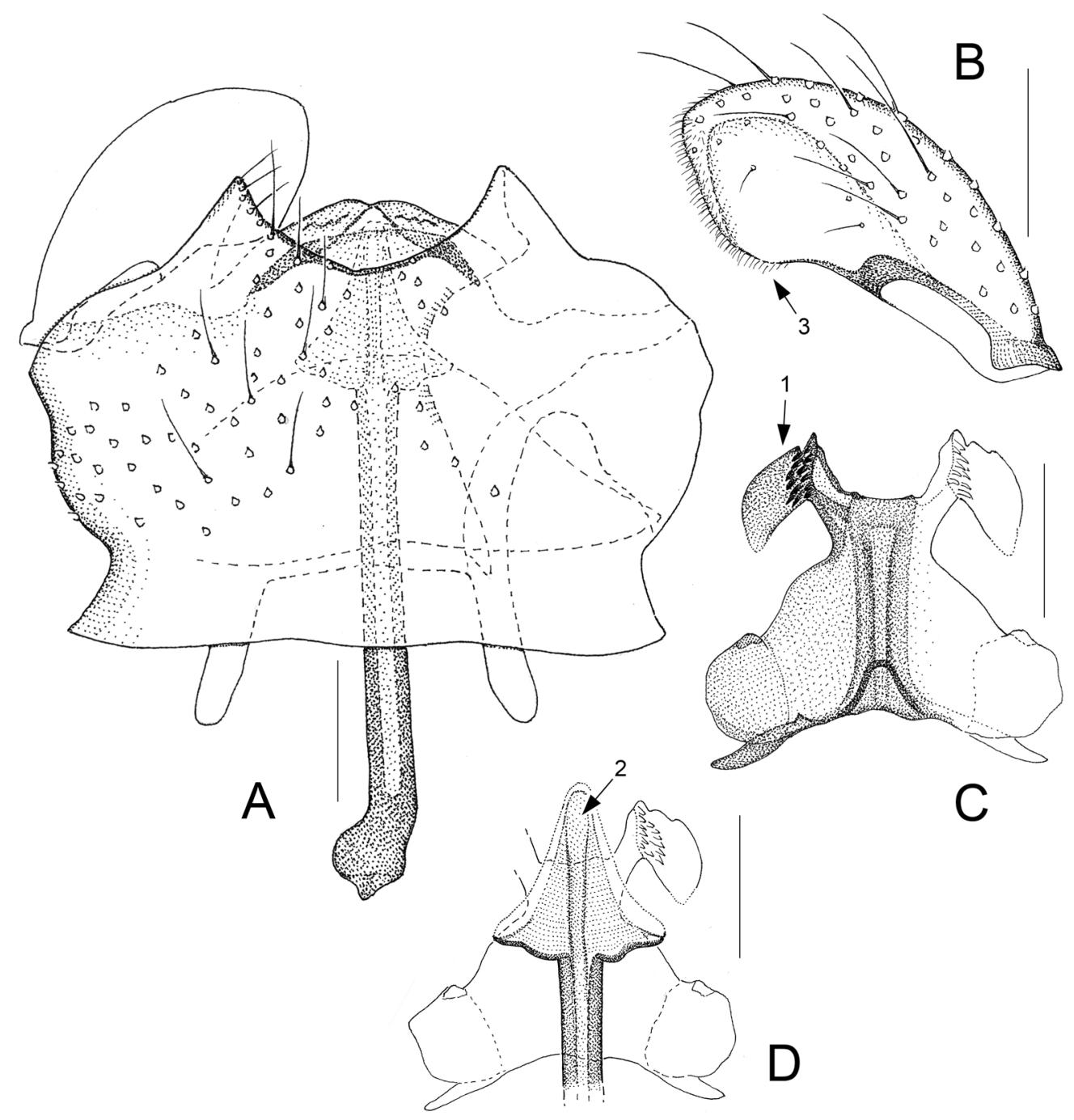

Fig. 20. Glemparon warra sp. nov., holotype, ô (AM, no. CEC1408). A. Genitalia, ventral. B. Gonostylus, ventral. C. Tegmen, ventral. D. Apex of ejaculatory apodeme, tegmen indicated, ventral. Scale bars $=0.05 \mathrm{~mm}$. Numbered arrows indicate diagnostic characters (see Diagnosis). 
concave portions medially and the angular-shaped, densely microtrichose apex (Fig. 20B). Ejaculatory apodeme conspicuously thick (Fig. 20A).

\section{Distribution and phenology}

The only specimen known of $G$. warra sp. nov. was Malaise trapped at the end of summer in the same habitat as the previous species.

\section{Discussion}

Taxonomic descriptions based on single specimens carry the risks of misinterpreting preparation artifacts as taxonomic characters and underestimating intraspecific variation (e.g., Jaschhof \& Jaschhof 2009). In the present study we used only perfectly prepared (slide-mounted) specimens, whose structures were not distorted or otherwise affected during the preparation process, thereby minimizing the artifact problem. Furthermore, genitalic structures, which provide the characters of diagnostic merit in Glemparon, rarely vary within a species. Even so, whenever we felt that limitation of our material might pose a problem, we interpreted our observations with special caution, such as in the case of G. waipoua sp. nov.

The genus Glemparon can serve as an example for the fact that monotypic genera are difficult to interpret (as there is little substance available to compare with), while the discovery of a single additional congener (here G. tomelilla sp. nov.) may function as a catalyzer for the cognitive process. This, we believe, proves the potency of the comparative morphological method for resolving questions of character evolution, phylogeny and classification. For example, the true nature of the tegminal longitudinal apodemes, previously thought to be just another kind of tegminal processes (see Jaschhof \& Jaschhof 2013), could be understood only by comparing its various different manifestations within a wide range of species. Another example is the structure called here the gonocoxal posteromedial protuberance; its complex structuring and relevance as a synapomorphy of Glemparon was only realized by comparative examination throughout the genus. Also, the generic definition of Glemparon changed fundamentally through the input of data from a number of newly discovered species. Last but not least, intimately knowing as many species of a genus as possible is crucial for realizing the systematic affiliation of species whose morphology is somehow aberrant (see, e.g., G. manuka sp. nov.), for which almost all speciose genera provide examples. In other words, describing new species matters, for they provide the raw data for all kinds of subsequent analyses - a causal relationship whose relevance for Cecidomyiidae and other "open-ended taxa" is sometimes questioned (see Bickel 2009).

We do not think that the disjunct, bipolar distribution of Glemparon as revealed by our study is a matter of real facts; rather it is the consequence of our collective ignorance of Porricondylinae diversity in most parts of the globe. Enough is known about Porricondylinae in the West Palearctic as to establish that Glemparon are uncommon and poor in species there; however, we are much more badly informed about the situation in the East Palearctic, not to speak about the Oriental region. At the same time there is no doubt that Glemparon is an enormously speciose genus in the Australasian region (and possibly even beyond), which was previously unknown. Considering that our small amount of study material was gathered more or less randomly, one wonders what a systematic search for Glemparon in trap samples from all over New Zealand and Australia would reveal. Our observation of five different species cooccurring at a single site also raises the question of how these species are adapted to different ecological niches in the smallest spaces. Thus far, our study has generated more question marks than it has removed - a typical situation with such basic taxonomic studies. Systematic research into Glemparon in the future should consider using morphology along with molecular genetic evidence for characterizing species, even though this means additional expenditures and adequately preserved specimens. As the case of G. waipoua sp. nov. shows, not all alpha-taxonomic problems in Glemparon can be solved using alone male adult characters. 


\section{Acknowledgements}

Work on this paper was conducted during funding for MJ by Svenska ArtDatabanken, The Swedish Species Information Centre, within the framework of Svenska Artprojektet, The Swedish Taxonomy Initiative (project dha2014-150 4.3). Specimens of Glemparon from New Zealand were either received on long-term loan from the New Zealand Arthropod Collection, for which we thank Trevor K. Crosby, or were collected by us on the basis of collecting permit 9900/142/3/04 issued for Peter M. Johns, whom we thank for his great support of our work in New Zealand, or were picked from Malaise samples placed at our disposal by Raphael K. Didham and Richard Toft. Specimens from Tasmania were received for taxonomic study from The Tasmanian Forest Insect Collection in the care of Forestry Tasmania, which was kindly arranged by Simon J. Grove. Our work in New Zealand was facilitated through research grants for MJ by The German Research Council (projects JA1020/1-1 and 1-2), and in Tasmania through a Warra Small Project Grant by Forestry Tasmania. Raymond J. Gagné was, once more, so kind to carefully review the manuscript before submission to the journal.

\section{References}

Bickel D. 2009. Why Hilara is not amusing: the problem of open-ended taxa and the limits of taxonomic knowledge. In: Pape T., Bickel D. \& Meier R. (eds) Diptera Diversity: Status, Challenges and Tools: 279-301. Koninklijke Brill, Leiden.

Jaschhof M. \& Jaschhof C. 2003. Wood midges of New Zealand (Cecidomyiidae, Lestremiinae). Part I: Introductory notes and tribes Lestremiini, Strobliellini, Campylomyzini and Pteridomyiini Jaschhof trib. nov. Studia Dipterologica 10: 97-132.

Jaschhof M. \& Jaschhof C. 2008. Catotrichinae (Diptera: Cecidomyiidae) in Tasmania, with the description of Trichotoca edentula gen. et sp. n. Zootaxa 1966: 53-61.

Jaschhof M. \& Jaschhof C. 2009. The wood midges (Diptera: Cecidomyiidae: Lestremiinae) of Fennoscandia and Denmark. Studia Dipterologica Supplement 18: 1-333.

Jaschhof M. \& Jaschhof C. 2013. The Porricondylinae (Diptera: Cecidomyiidae) of Sweden, with notes on extralimital species. Studia dipterologica Supplement 20: 1-392.

Jaschhof M. \& Spungis V. 2018. Towards reliable identification of male Dicerura: descriptions of three new and seven poorly known species in the Palearctic region (Diptera: Cecidomyiidae, Porricondylinae). Zootaxa, 4422 (1): 85-103. https://doi.org/10.11646/zootaxa.4422.1.5

Manuscript received: 27 March 2018

Manuscript accepted: 15 May 2018

Published on: 17 July 2018

Topic editor: Gavin Broad

Desk editor: Pepe Fernández

Printed versions of all papers are also deposited in the libraries of the institutes that are members of the EJT consortium: Muséum national d'Histoire naturelle, Paris, France; Botanic Garden Meise, Belgium; Royal Museum for Central Africa, Tervuren, Belgium; Natural History Museum, London, United Kingdom; Royal Belgian Institute of Natural Sciences, Brussels, Belgium; Natural History Museum of Denmark, Copenhagen, Denmark; Naturalis Biodiversity Center, Leiden, the Netherlands; Museo Nacional de Ciencias Naturales-CSIC, Madrid, Spain; Real Jardín Botánico de Madrid CSIC, Spain; Zoological Research Museum Alexander Koenig, Bonn, Germany. 